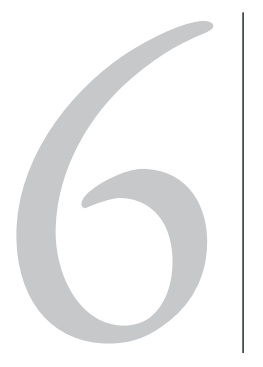

\title{
LA SITUACIÓN FISCAL DE LAS CIUDADES ARGENTINAS
}

\author{
THE FISCAL SITUATION OF
}

ARGENTINE CITIES

\begin{abstract}
Martín Luis Mangas ${ }^{1}$
Alejandro López Accotto ${ }^{2}$

Carlos Rodolfo Martínez ${ }^{3}$

Recibido: 08/10/2016

Aceptado: 05/12/2016
\end{abstract}

\section{RE S U M E N}

El presente artículo tiene por objetivo dar cuenta, para el caso argentino, de la situación actual y evolución reciente de una serie de variables relevantes para el análisis del desempeño fiscal de los gobiernos de nivel municipal. Atento a ello, se presentan datos referidos a cuestiones tales como la composición de los ingresos y gastos municipales, la autonomía financiera, el resultado financiero, el autofinanciamiento y la inversión pública local. A su vez, dada la profunda heterogeneidad territorial del país, dicha información se trabajan para las distintas regiones que lo componen y para las distintas escalas poblacionales. Todo ello en el entendimiento de que, fortalecer el financiamiento de los gobiernos locales, es clave para obtener una provisión pública local de bienes y servicios, con un piso de homogeneidad en términos de calidad, cantidad y accesibilidad, en todo el territorio nacional.

\section{PALA B R S C L AVES \\ Administración pública local, finanzas municipales.}

1. Universidad Nacional de General Sarmiento, Buenos Aires, Argentina. Correo: mmangas@ungs.edu.ar

2. Universidad Nacional de General Sarmiento, Buenos Aires, Argentina. Correo: alopez@ungs.edu.ar

3. Universidad Nacional de General Sarmiento, Buenos Aires, Argentina. Correo: cmartinez@ungs.edu.ar 


\section{A B S T R A C T}

The present article aims to give an account, for the Argentine case, of the current situation and recent evolution of a series of variables relevant for the analysis of the fiscal performance of the municipal level governments. Attention is given to data on issues such as the composition of municipal revenues and expenditures, financial autonomy, financial results, self-financing and local public investment. In turn, given the country's profound territorial heterogeneity, this information is worked for the different regions that compose it and for the different population scales. All this in the understanding that, strengthening the financing of local governments, is key to obtaining a local public supply of goods and services, with a floor of homogeneity in terms of quality, quantity and accessibility, throughout the national territory.

\section{K E Y W O R D S}

Local public administration, municipal finance.

\section{I N T R O D U C C I Ó N}

La República Argentina tiene un sistema federal de gobierno que se caracteriza por un federalismo fiscal basado en un sistema de transferencias financieras intergubernamentales que distribuye recursos de la Nación a las provincias y de ellas a los municipios.

La institucionalidad municipal es muy variada, porque las provincias definen categorías diferentes de municipios, relacionadas con el número de habitantes. Según el Censo Nacional, en 2010 había 2.294 gobiernos locales, aunque sólo 1.102 están constituidos como municipios. Además del aspecto institucional, los municipios argentinos presentan una notable heterogeneidad en diversas dimensiones; densidad de población, desarrollo económico, pobreza, cobertura de servicios públicos, superficie y población, tanto entre provincias como al interior de cada una de ellas.

El gobierno de las ciudades es responsabilidad de los municipios pero, en los grandes aglomerados urbanos, es frecuente que coexistan territorios de diferentes municipios e, incluso, de municipios de diferentes provincias. La excepción a esta regla es la Ciudad Autónoma de Buenos Aires que es gobernada por una autoridad que se asimila más a la escala provincial que a la municipal. Al mismo tiempo, la Ciudad Autónoma de Buenos Aires comparte un territorio con 24 municipios que pertenecen a la provincia de Buenos Aires denominada Área Metropolitana de Buenos Aires. Allí se concentran el 31,92\% de la población total del país y se presenta un entra- 
mado complejo en términos de actores institucionales. A su vez, la Constitución Nacional de 1994 determina que el régimen municipal es potestad de cada provincia, razón por la cual existen en nuestro país veintitrés legislaciones diferentes, con diversas configuraciones de origen y distribución de recursos. Esta situación relativiza la representatividad de los valores medios agregados.

La composición institucional lleva a una situación en la cual las misiones y funciones que se adjudican a la institución municipal son diferentes en las distintas provincias. Sin embargo, en términos generales, en el marco institucional de todas ellas se determinan como funciones principales de los municipios los servicios especiales urbanos que comprenden el alumbrado, el barrido y la limpieza de calles, incluyendo la recolección de residuos domiciliarios, el trazado de calles, el control urbanístico, la regulación y control del tránsito de vehículos, la conservación de monumentos y valores locales, el control sobre la radicación y funcionamiento de las actividades económicas (especialmente comerciales e industriales) incluyendo la inspección de sus condiciones de higiene y seguridad, la sanidad en general y la asistencia social.

Como se puede apreciar, se trata de una gama muy amplia de funciones, que se desempeñan con distinta intensidad según el entramado institucional de cada provincia y las características propias de cada municipio. En el caso de los municipios urbanos de grandes dimensiones o de municipios que participan en grandes aglomerados, ha habido un creciente aumento de las funciones así como una mayor complejidad de las mismas. Dicha tendencia surge por una combinación de las siguientes circunstancias:

a) La transferencia explícita y mediante algún tipo de norma u acto administrativo, de una determinada función, desde el Estado Nacional o Provincial, hacia los gobiernos locales, tal como puede suceder con ciertas actividades vinculadas con la salud, la educación o la seguridad ciudadana, por dar algunos ejemplos.

b) La transferencia, implícita y sin ningún tipo de respaldo normativo que la sustente, de determinadas actividades, desde el gobierno provincial o nacional, hacia los gobiernos locales, que se produce cuando dichas acciones dejan de ser desarrolladas por las jurisdicciones de nivel superior o son desarrolladas en forma insuficiente o inadecuada.

c) El surgimiento de nuevos campos de política, desarrollados por los gobiernos locales en razón de su mayor cercanía con la población y no siempre 
debidamente contemplados en la distribución de recursos financieros entre niveles de gobierno, que modifican y amplían la agenda pública, incorporando temáticas, problemas y enfoques novedosos, entre los que pueden citarse el fomento al desarrollo local, la protección del medio ambiente, la intensificación de la experiencia democrática vía la promoción de distintos canales de participación ciudadana y comunitaria y las políticas dirigidas a mejorar la convivencia en las grandes aglomeraciones urbanas.

El presente estudio, se basa en una selección de aglomerados urbanos y municipios que alcanza los 277 casos en todo el país (ver anexo metodológico), cubriendo a unos 26,5 millones de personas (66\% de la población argentina). El trabajo, a partir de indicadores de recursos, gastos, autonomía financiera, autofinanciamiento y resultado financiero, busca presentar los principales resultados de la situación fiscal municipal, teniendo en cuenta las distintas realidades regionales y de las distintas escalas de gobiernos locales.

\section{L A C UEST I Ó N F I S C A L}

En primer lugar, la distribución media global y evolución de ingresos y gastos por nivel de gobierno permite apreciar el peso de lo municipal:

\section{CUADRO $N \div 1$ \\ DISTRIBUCIÓN DE INGRESOS Y GASTOS POR NIVEL DE GOBIERNO / AÑOS 1993 Y 2013}

\begin{tabular}{lcccc} 
NIVEL DE GOBIERNO & \multicolumn{2}{c}{ INGRESOS } & \multicolumn{2}{c}{ GASTOS } \\
& 1993 & 2013 & 1993 & 2013 \\
NACIONAL & $78 \%$ & $80 \%$ & $52 \%$ & $58 \%$ \\
PROVINCIAL & $16 \%$ & $16 \%$ & $39 \%$ & $33 \%$ \\
MUNICIPAL & $6 \%$ & $4 \%$ & $9 \%$ & $9 \%$ \\
\hline
\end{tabular}

FUENTE: UNIVERSIDAD NACIONAL DE GENERAL SARMIENTO (UNGS) Y SECRETARÍA DE ASUNTOS MUNICIPALES DE LA NACIÓN (SAM) (2015).

La participación de los municipios en el gasto público se ha mantenido constante. En materia de ingresos existió una merma considerable, por lo tanto, la dependencia de las transferencias de las otras jurisdicciones (Nación y Provincias) ha aumentado en forma sensible, como forma de compensar el desequilibrio entre ingresos y gastos. Los municipios pasaron de tener una autonomía financiera del $66 \%$ a una del $44 \%$. Dicha realidad general contiene experiencias muy heterogéneas (Rezk y Abraham, 2013) de allí la importancia de dar cuenta de la situación en las distintas 
regiones y para las diferentes escalas de aglomeración de la población.

Ello da cuenta del mayor protagonismo de los municipios en distintas funciones de gastos, que se corresponde con el hecho de que no ha disminuido la participación del nivel municipal en el gasto consolidado (del Estado argentino en todos sus niveles) en un período de fuerte incremento de la importancia del accionar estatal en la economía y de una mayor transferencia de recursos para cubrirlos. Es decir, en términos globales, el incremento en las funciones no ha sido cubierto con incrementos en las potestades tributarias locales o en las prácticas recaudatorias municipales.

\section{CUADRO $N=2$}

PRESIÓN FISCAL POR NIVEL DE GOBIERNO EN PORCENTAJE DEL PBI. AÑOS SELECCIONADOS

$\begin{array}{llllll}\text { NIVEL DE GOBIERNO } & 1993 & 1998 & 2003 & 2008 & 2013 \\ \text { Nacional } & & & & & \\ \text { Provincial } & 17,9 \% & 17,1 \% & 19,6 \% & 26,3 \% & 32,1 \% \\ \text { Municipal } & 3,7 \% & 3,9 \% & 3,8 \% & 4,4 \% & 6,5 \% \\ \text { Total } & 1,2 \% & 1,3 \% & 1,2 \% & 1,0 \% & 1,4 \% \\ & \mathbf{2 2 , 8} \% & \mathbf{2 2 , 3} \% & \mathbf{2 4 , 6} \% & \mathbf{3 1 , 7} \% & \mathbf{4 0 , 0} \%\end{array}$

FUENTE: UNGS Y SAM (2015). NOTA: POR PRESIÓN FISCAL SE ENTIENDE LA RELACIÓN ENTRE LA RECAUDACIÓN DE IMPUESTOS, TASAS, DERECHOS Y CONTRIBUCIONES, EN RELACIÓN AL PBI.

La presión fiscal del total de las jurisdicciones municipales ha variado entre 1,0\%-1,4\% entre 1993 y 2013. Se nota un ascenso importante en los últimos cinco años, con un crecimiento del orden del 40\% entre 2008 y 2013, que ha superado el registrado en la presión fiscal total (26\%) y en la presión fiscal del Estado nacional (22\%), en igual período.

Sin embargo, su participación en la presión fiscal consolidada (nacional, provincial y municipal) en 1993 representaba el 5,3\% del total, cayendo en 2013 al 3,5\%. Para recuperar un peso similar al del año 1993, la presión fiscal municipal debería incrementarse en un 50\%, es decir, superando el $2 \%$ del PBI.

Explorar la presión fiscal del conjunto de tasas, derechos y contribuciones sobre la población da una idea aproximada del esfuerzo realizado por los ciudadanos para sostener los servicios públicos locales: 


\section{GRÁFICO No 1. PRESIÓN FISCAL MUNICIPAL. RECAUDACIÓN TOTAL DE TASAS, DERECHOS Y CONTRIBUCIONES, PER CÁPITA, EN PESOS. AÑO 2013}

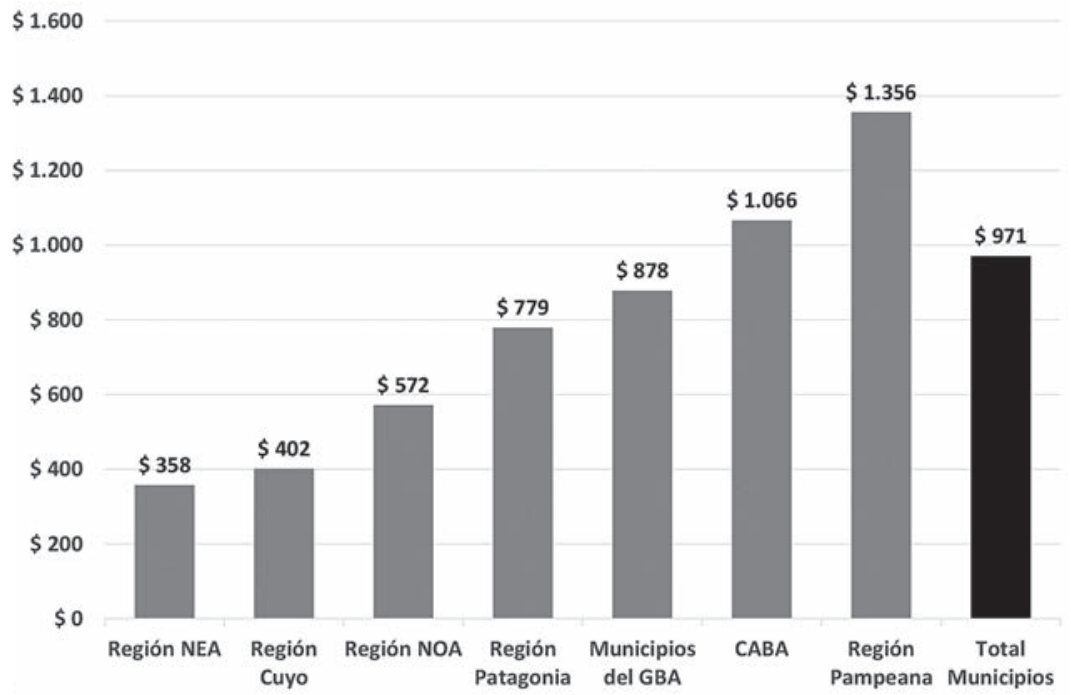

$\$ 1.600$

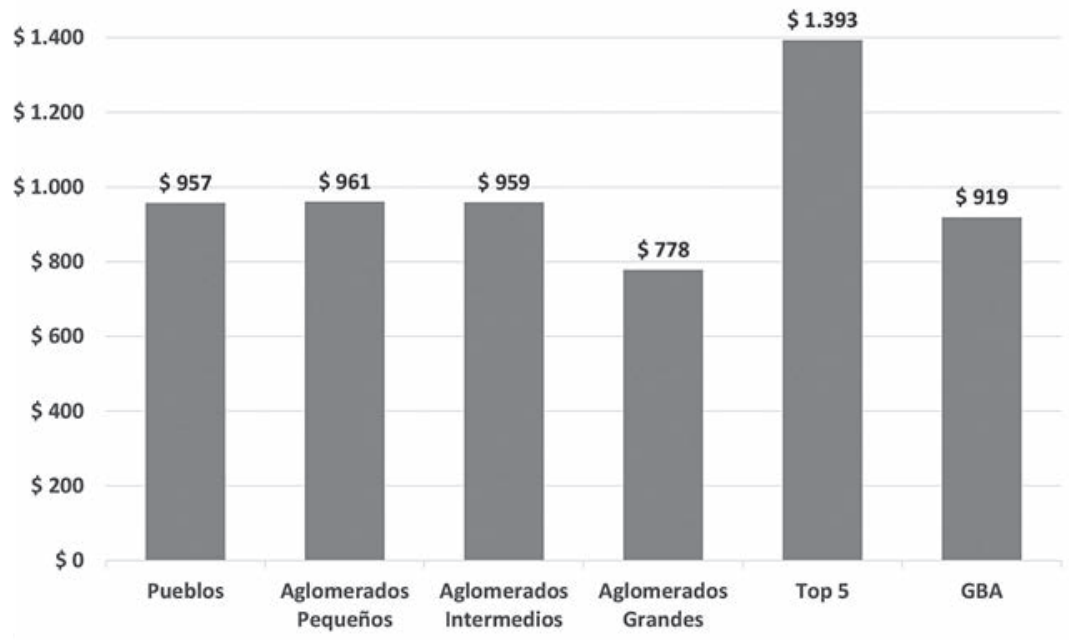

FUENTE: ELABORACIÓN PROPIA SEGÚN INFORMACIÓN PROVENIENTE DE LOS MUNICIPIOS.

NOTA: LOS DATOS DE CABA NO SE INCLUYEN EN GBA NI EN TOTAL MUNICIPIOS EN EL GRÁFICO POR REGIÓN Y SÍ SE INCLUYEN EN GBA EN EL GRÁFICO POR ESCALA POBLACIONAL.

NOTA: PUEBLOS: POBLACIÓN ENTRE 2.000 Y 50.000. AGLOMERADOS PEQUEÑOS: POBLACIÓN ENTRE 50.000 Y 100.000. AGLOMERADOS INTERMEDIOS: POBLACIÓN ENTRE 100.000 Y 300.000. AGLOMERADOS GRANDES: MUNICIPIOS DE AGLOMERADOS CON ENTRE 300.000 Y 700.000 HABITANTES. TOP 5: MUNICIPIOS DE AGLOMERADOS CON ENTRE 700.000 Y 1.500.000 HABITANTES. GBA: GRAN BUENOS AIRES. CABA: CIUDAD AUTÓNOMA DE BUENOS AIRES. 
En promedio, la población abona menos de tres pesos diarios per cápita por la totalidad de las tasas, derechos y contribuciones municipales. En el caso de los aglomerados entre 700.000 y un millón y medio de personas este indicador asciende a casi cuatro pesos diarios. El pago fiscal municipal per cápita aumenta claramente con el tamaño del municipio. Los habitantes de los grandes aglomerados urbanos del interior del país soportan una carga fiscal que es cerca del doble de la media nacional. Tal como sucede, por ejemplo, en los casos del Gran Córdoba (\$1.917) y del Gran Bahía Blanca (\$1.852).

\section{LA C OMPOSICIÓN DE L OS INGRESOS M U N I C I PA L E S}

Los municipios argentinos, para el financiamiento de las políticas públicas, cuentan con una serie de recursos que provienen tanto de la propia recaudación de impuestos, tasas, derechos, contribuciones y otros como de distintas transferencias (corrientes y de capital), del Estado Nacional y de las provincias. Algunas transferencias son automáticas (como la coparticipación provincial y el Fondo Federal Solidario) y otras no automáticas.

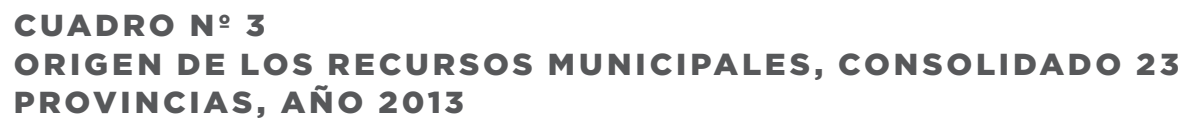

\section{CONCEPTO}

Tasas, derechos y contribuciones

Otros recursos propios corrientes (impuestos, regalías y otros)

Subtotal Recursos Propios Corrientes

Recursos corrientes de origen nacional y provincial

Total Recursos Corrientes

Fondo Federal Solidario

Otros recursos de capital

TOTAL

\section{PARTICIPACIÓN}

$35 \%$

$7 \%$

$42 \%$

$48 \%$

$90 \%$

$2 \%$

$8 \%$

$100 \%$

FUENTE: ELABORACIÓN PROPIA SEGÚN INFORMACIÓN PROVENIENTE DE LOS MUNICIPIOS. NOTA: NO INCLUYE CABA.

Así, un $42 \%$ de los recursos corrientes municipales son propios (tasas, derechos y contribuciones, impuestos, regalías y otros) y, de ellos, más del $80 \%$ corresponden a la categoría de tasas, derechos y contribuciones. Con respecto a la potestad de los municipios para recaudar impuestos, sólo algunas provincias han transferido potestades impositivas a los municipios (quienes pueden así decidir cuánto se va a cobrar y a quien, y se quedan con 
la totalidad del monto recaudado de los respectivos tributos), especialmente el impuesto a los automotores y el impuesto inmobiliario urbano:

CUADRO NN 4

POTESTADES TRIBUTARIAS DELEGADAS

\begin{tabular}{|c|c|c|c|c|}
\hline PROVINCIAS & $\begin{array}{l}\text { INGRESOS BRUTOS } \\
\text { DIRECTO }\end{array}$ & INMOBILIARIO URBANO & INMOBILIARIO RURAL & AUTOMOTOR \\
\hline Chaco & No & $\mathrm{Si}$ & No & $\mathrm{Si}$ \\
\hline Chubut & $\mathrm{Si}$ & $\mathrm{Si}$ & $\mathrm{Si}$ & $\mathrm{Si}$ \\
\hline Córdoba & No & No & No & $\mathrm{Si}$ \\
\hline Corrientes & No & $\mathrm{Si}$ & No & $\mathrm{Si}$ \\
\hline Formosa & No & $\mathrm{Si}$ & No & $\mathrm{Si}$ \\
\hline Jujuy & No & No & No & $\mathrm{Si}$ \\
\hline Neuquén & No & No & No & $\mathrm{Si}$ \\
\hline Salta & No & $\mathrm{Si}$ & No & $\mathrm{Si}$ \\
\hline Santa Cruz & No & $\mathrm{Si}$ & No & $\mathrm{Si}$ \\
\hline Tierra del Fuego & No & $\mathrm{Si}$ & No & $\mathrm{Si}$ \\
\hline
\end{tabular}

FUENTE: UNGS Y SAM (2015).

En el resto del país, las potestades tributarias han sido retenidas por el nivel provincial de gobierno, independientemente de que algún tramo de ciertos impuestos pueda ser recaudado por los municipios, en nombre de las provincias.

Así, en la provincia de Buenos Aires no se ha producido una descentralización tributaria, sino una mera desconcentración de la función, donde los municipios recaudan, en nombre del gobierno provincial algunos tramos de diversos impuestos (pequeños contribuyentes de ingresos brutos, patentes de automotores de más de diez años de antigüedad e inmobiliario rural), pero la potestad sobre el impuesto (a quien y cuanto recaudar) la retiene el gobierno provincial. A su vez, los municipios bonaerenses transfieren lo recaudado al gobierno provincial, reteniendo para sí solamente un porcentaje menor, en concepto de comisión por el servicio de recaudación.

Por su parte, el Gobierno de la Ciudad Autónoma de Buenos Aires concentra potestades tributarias tanto del nivel provincial (impuestos a los ingresos brutos, inmuebles, automotores, sellos y otros) como del municipal (tasas por alumbrado, barrido y limpieza, por inspección de seguridad e higiene y otras tasas, derechos y contribuciones) sin que se haya producido en su territorio descentralización alguna (como podría suceder, por ejemplo, al descentralizarse a sus comunas alguna potestad sobre impuestos o tasas).

En cuanto a los recursos corrientes provenientes de otras jurisdicciones, los 
más importantes son los que se reciben a través de los sistemas de coparticipación provinciales (Sanguinetti, Sanguinetti y Tommasi, 2001), ya que no existe coparticipación directa de Nación a municipios, sino que cada provincia coparticipa parte de sus recursos, entre los que se incluyen los recibidos en concepto de coparticipación federal de impuestos, con sus municipios. Cada provincia ha legislado acerca de la forma en que realiza tal distribución. Suele tratarse de una legislación antigua y con criterios de distribución poco racionales, tales como el reparto de una parte significativa de la coparticipación por partes iguales (sin atender las diferencias entre distintos territorios ni la heterogeneidad del colectivo municipal), gran peso de criterios devolutivos (que brindan más transferencias a los municipios con mayores recursos propios y, por ende, menor necesidad de asistencia financiera) y poca relevancia de criterios distributivos que son aquellos que buscan garantizar un piso de financiamiento, a partir de un enfoque de derechos que considera que es necesario garantizar un mínimo nivel de bienes y servicios públicos, sin importar el lugar de residencia de la población nacional (López Accotto, Martínez, Grinberg y Mangas, 2013). El peso relativo de estos distintos criterios en cada provincia, se detallan en el Cuadro $\mathrm{N}^{\circ} 6$.

Las principales dimensiones que se consideran en los regímenes de coparticipación (Porto, 1999) son: a) la masa coparticipable, que establece cuales son los ingresos a distribuir; b) la distribución primaria que define que parte de los ingresos quedan para la provincia y que parte se reparte a los municipios y c) la distribución secundaria donde se establece como se distribuyen los recursos asignados a los municipios entre todos ellos. Cuestiones que se observan en los Cuadros $\mathrm{N}^{\circ} 5$ y $\mathrm{N}^{\circ} 6$.

Como ya se ha mencionado, tres provincias (Jujuy, La Rioja y San Juan), no tienen vigente el régimen de coparticipación y, por lo tanto, distribuyen los recursos a través de leyes anuales específicas o mediante convenios. El resto de las provincias distribuyen a los municipios entre un $8 \%$ (San Luis) y un 30\% (Tierra del Fuego) de lo que ellas reciben de la Coparticipación Federal de Impuestos. También distribuyen proporciones muy diferentes de sus ingresos tributarios propios (impuestos provinciales). Los porcentajes aquí fluctúan entre un $13 \%$ y un $32 \%$. El dato desagregado por provincia se presenta en el Cuadro $\mathrm{N}^{\circ} 5$, mientras que en el Cuadro $\mathrm{N}^{\circ} 6$ se detallan los criterios que se utilizan en cada provincia para determinar cuánto le corresponde a sus municipios. 


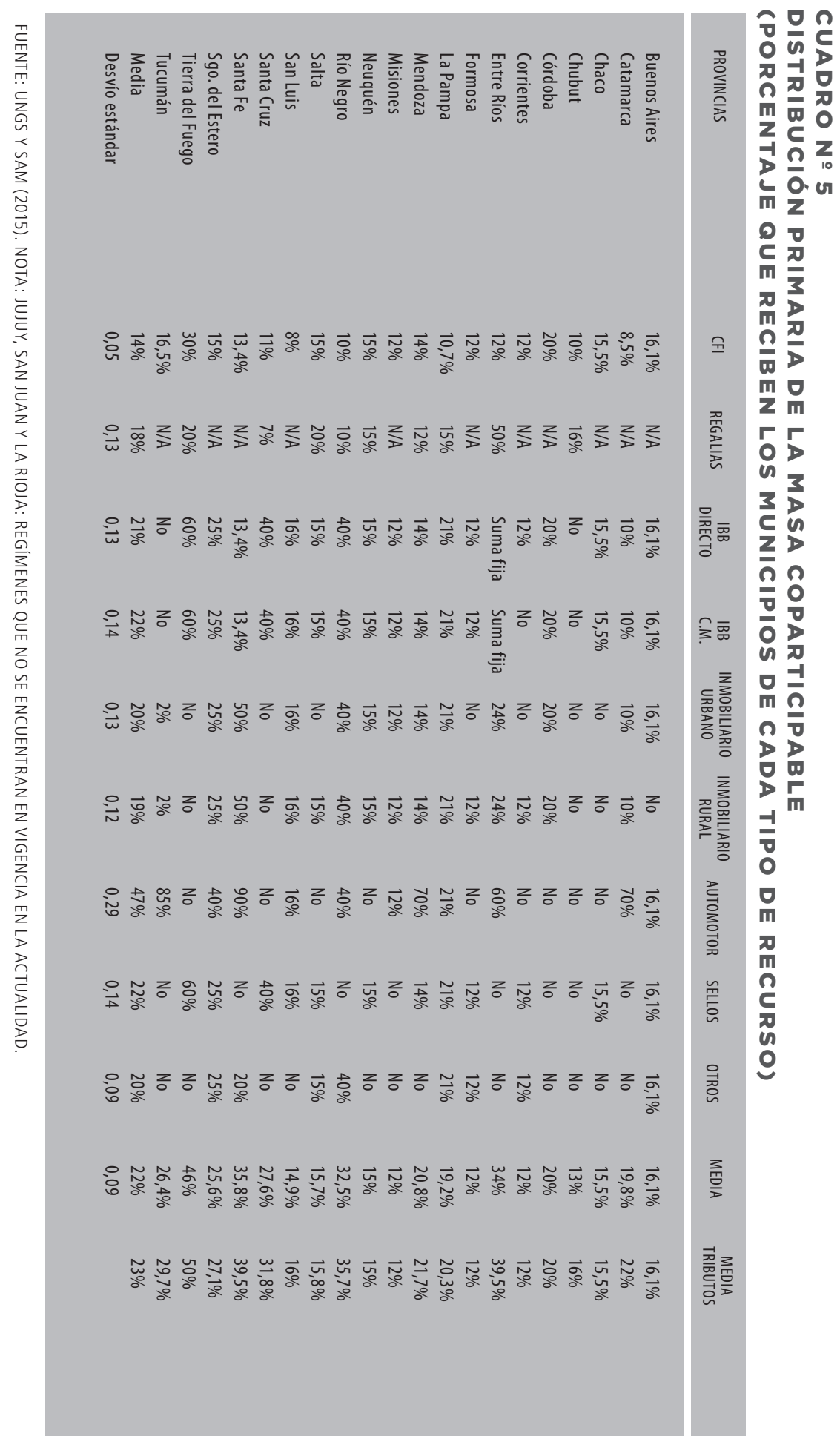


CUADRO N 6

DISTRIBUCIÓN PRIMARIA DE LA MASA COPARTICIPABLE (PESO DE CADA CRITERIO DE REPARTO ENTRE MUNICIPIOS, POR PROVINCIA)

\begin{tabular}{|c|c|c|c|c|c|c|c|c|c|c|c|c|c|c|c|c|c|c|c|c|}
\hline & 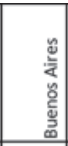 & 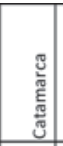 & $\begin{array}{l}8 \\
0 \\
5 \\
\end{array}$ & \begin{tabular}{|l|}
5 \\
0 \\
3 \\
5 \\
5
\end{tabular} & \begin{tabular}{|l|}
0 \\
0 \\
0 \\
0
\end{tabular} & 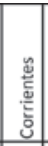 & 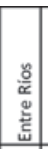 & 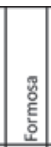 & 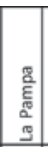 & 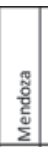 & 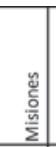 & 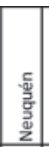 & 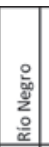 & $\frac{\mathscr{g}}{\mathrm{m}}$ & 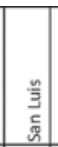 & 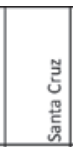 & 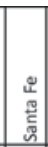 & 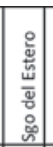 & 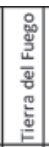 & 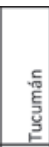 \\
\hline Población & $35,96 \%$ & $66,5 \%$ & & $80 \%$ & $79 \%$ & $98 \%$ & & $40 \%$ & $20 \%$ & $65 \%$ & & $60 \%$ & $40 \%$ & $30 \%$ & $80 \%$ & $83,15 \%$ & $40 \%$ & $44 \%$ & $8 \%$ & \\
\hline \begin{tabular}{|l|l|} 
Electores \\
\end{tabular} & & & & & & & $34 \%$ & & & & & & & & & & & & & \\
\hline \begin{tabular}{|l|} 
Diferencia Poblacional con la Capital \\
\end{tabular} & & & & & & & & & & & & & & & & $5,85 \%$ & & & & \\
\hline \begin{tabular}{|l|} 
Población Rural \\
\end{tabular} & & & & & & & & & & & & $10 \%$ & & & & & & $2 \%$ & & \\
\hline Distancia de la Capital & & & & & & & & & & & & & & & $2,5 \%$ & & & & & \\
\hline Inversa Población & & & & & & $2 \%$ & & & & & & & & & & & & $1 \%$ & & \\
\hline Partes Iguales & & $18 \%$ & $15 \%$ & $20 \%$ & $21 \%$ & & $36 \%$ & $30 \%$ & $5 \%$ & $25 \%$ & & $5 \%$ & $20 \%$ & & $15 \%$ & $11 \%$ & $30 \%$ & $1 \%$ & $44 \%$ & \\
\hline Superficie & $8,7 \%$ & $1,5 \%$ & & & & & & & & & & & & & & & & & & \\
\hline Recaudación Recursos Propios & & $3 \%$ & $25 \%$ & & & & $25 \%$ & $30 \%$ & $40 \%$ & & & $10 \%$ & $40 \%$ & & & & $30 \%$ & $50 \%$ & $48 \%$ & \\
\hline Recaudación Impuestos Provinciales & & & & & & & & & $35 \%$ & & & & & & & & & & & \\
\hline Gastos Corrientes & & & & & & & & & & & & & & $35 \%$ & & & & & & \\
\hline Gastos de Capital & & $3 \%$ & & & & & & & & & & & & & & & & & & \\
\hline Gasto Total por habitante & & & & & & & & & & & & & & $35 \%$ & & & & & & \\
\hline Empleados Municipales & & $8 \%$ & $60 \%$ & & & & & & & & & & & & & & & $1 \%$ & & \\
\hline Prestaciones de Salud Municipales & $37,13 \%$ & & & & & & & & & & & & & & & & & & & \\
\hline Necesidades Básicas Insatisfechas & & & & & & & $5 \%$ & & & & & & & & $2,5 \%$ & & & $1 \%$ & & \\
\hline Inversa Costo Salarial por habitante & & & & & & & & & & & & $15 \%$ & & & & & & & & \\
\hline Inversa Capacidad Contributiva & $13,34 \%$ & & & & & & & & & & & & & & & & & & & \\
\hline Coeficientes Fijos & $4,87 \%$ & & & & & & & & & $10 \%$ & $100 \%$ & & & & & & & & & $100 \%$ \\
\hline
\end{tabular}

FUENTE: ELABORACIÓN PROPIA A PARTIR DE CASAÑO Y AGÜERO (2008), PG. 26. NOTA: JUJUY, SAN JUAN Y LA RIOJA POSEEN REGÍMENES QUE NO SE ENCUENTRAN EN VIGENCIA EN LA ACTUALIDAD.

Por último, existen normas específicas relativas a un tipo de transferencia automática de recursos de origen nacional a los municipios: el Fondo Federal Solidario (FFS). El FFS distribuye entre todas las provincias argentinas el 30\% de la recaudación de las retenciones a las exportaciones de soja (cuyo monto total depende tanto del volumen exportado como del precio internacional). De lo recibido, los gobiernos provinciales se comprometen a destinar el $70 \%$ y a distribuir el $30 \%$ restante entre sus municipios, que también deben asignar dichos recursos al gasto de capital. Estas transferencias se caracterizan por no ser completamente de libre disponibilidad (en tanto deben dedicarse a erogaciones de capital y no pueden financiar gastos corrientes ni aplicaciones financieras), aunque brindan a los municipios amplios márgenes de maniobra, en tanto pueden decidir por sí mismos el destino de dichos fondos, siempre dentro de los gastos de capital. Así, en relación al universo de dichos tipos de gastos, el FFS presenta una relevancia significativa, que varía de acuerdo a la región y escala poblacional de los aglomerados urbanos, tal como puede apreciarse más adelante en el Retomando los asuntos más generales, para la muestra seleccionada, la composición de los recursos corrientes es la siguiente: 
CUADRO NN 7

COMPOSICIÓN PROMEDIO DE LOS RECURSOS CORRIENTES MUNICIPALES, AÑO 2013

\begin{tabular}{lccccc|}
\hline REGIÓN & $\begin{array}{c}\text { TASAS, DERECHOS } \\
\text { Y CONTRIBUCIONES }\end{array}$ & IMPUESTOS & $\begin{array}{c}\text { REGALIAS } \\
\text { OTROS REC. }\end{array}$ & $\begin{array}{c}\text { RECURSOS NO PROPIOS } \\
\text { CORIENTES PROPIOS }\end{array}$ \\
$\begin{array}{llllll}\text { (COPAR.Y OTROS) } \\
\text { Municipios del GBA }\end{array}$ & $44 \%$ & $0 \%$ & $0 \%$ & $5 \%$ & $51 \%$ \\
Región Pampeana & $41 \%$ & $1 \%$ & $0 \%$ & $5 \%$ & $53 \%$ \\
Región Cuyo & $21 \%$ & $0 \%$ & $0 \%$ & $5 \%$ & $74 \%$ \\
Región NOA & $27 \%$ & $3 \%$ & $0 \%$ & $2 \%$ & $68 \%$ \\
Región NEA & $21 \%$ & $7 \%$ & $0 \%$ & $3 \%$ & $69 \%$ \\
Región Patagónica & $22 \%$ & $11 \%$ & $10 \%$ & $5 \%$ & $52 \%$ \\
Total Municipios & $38 \%$ & $2 \%$ & $1 \%$ & $5 \%$ & $54 \%$ \\
CABA & $7 \%$ & $81 \%$ & $0 \%$ & $3 \%$ & $9 \%$ \\
& & & & & \\
\hline
\end{tabular}

FUENTE: ELABORACIÓN PROPIA SEGÚN INFORMACIÓN PROVENIENTE DE LOS MUNICIPIOS. NOTA 1: MUNICIPIOS DEL GBA Y TOTAL MUNICIPIOS NO INCLUYE CABA. NOTA 2: EN ALGUNAS PROVINCIAS LOS MUNICIPIOS CONSIDERAN A LAS REGALÍAS COMO RECURSOS PROPIOS AUNQUE ESTRICTAMENTE SU PERCEPCIÓN ES UNA POTESTAD PROVINCIAL.

$\begin{array}{lccccc}\text { TAMAÑO } & \begin{array}{c}\text { TASAS, DERECHOS } \\ \text { YCONTRIBUCIONES }\end{array} & \text { IMPUESTOS } & \text { REGALIAS } & \begin{array}{c}\text { OTROS REC. } \\ \text { CORRIENTES PROPIOS }\end{array} & \begin{array}{c}\text { RECURSOS NOPROPIOS } \\ \text { (COPAR. Y OTROS) }\end{array} \\ \text { GBA } & 18 \% & 56 \% & 0 \% & 3 \% & 23 \% \\ \text { Top 5 } & 48 \% & 2 \% & 0 \% & 6 \% & 44 \% \\ \text { Aglomerados Grandes } & 35 \% & 3 \% & 0 \% & 4 \% & 58 \% \\ \text { Aglomerados Intermedios } & 38 \% & 4 \% & 3 \% & 4 \% & 51 \% \\ \text { Aglomerados Pequeños } & 33 \% & 2 \% & 0 \% & 6 \% & 59 \% \\ \text { Pueblos } & 25 \% & 1 \% & 1 \% & 4 \% & 69 \%\end{array}$

FUENTE: ELABORACIÓN PROPIA SEGÚN INFORMACIÓN PROVENIENTE DE LOS MUNICIPIOS. NOTA: GBA INCLUYE CABA.

El análisis por región geográfica, permite apreciar, como en las regiones de Cuyo, NOA y NEA el nivel de dependencia de las transferencias nacionales y provinciales es muy elevado. Explica cerca de siete de cada diez pesos del total de recursos corrientes. Como contrapartida, en esas regiones, la recaudación de las tasas, derechos y contribuciones tiene una escasa incidencia en el total. El financiamiento a través de impuestos se focaliza en los municipios de la Patagonia (Chubut, Santa Cruz, Tierra del Fuego y Neuquén), en el NEA (Chaco, Formosa y Corrientes), y en menor medida en el NOA (Salta y Jujuy). En la región Pampeana, sólo los municipios de Córdoba poseen estas facultades. La Ciudad Autónoma de Buenos Aires financia nueve de cada diez pesos con sus impuestos y tasas, siendo su dependencia de las transferencias de otros niveles de gobierno (Nación) muy exigua.

La explotación de los bosques, el subsuelo o las aguas, conlleva a que los municipios perciben una parte de las regalías abonadas por el desarrollo de tales actividades (el resto lo retienen los gobiernos provinciales). Suelen ser recursos de libre disponibilidad, en los que la potestad tributaria es provincial, aunque se consideran recursos propios municipales. Este tipo 
de financiamiento reviste particular importancia en la región Patagónica donde es relevante la extracción de petróleo y gas.

Bajo la denominación genérica de "Otros recursos corrientes propios" se engloba toda una serie de recursos corrientes tales como: el cobro de multas (por contravenciones, infracciones e incumplimientos fiscales), cánones (a la explotación de predios e instalaciones municipales), rentas de la propiedad (alquileres de bienes muebles e inmuebles, intereses por pagos retrasados de tributos municipales y otros activos financieros de los gobiernos locales), venta de bienes (producidos por el propio municipio) y servicios (como los prestados por medio de maquinaria vial municipal) e ingresos de operación (por ejemplo de teatros, cines y otros establecimientos deportivos, culturales y recreativos municipales, e incluso de empresas públicas municipales). Tanto en el corte regional o por tamaño su incidencia explica entre dos y cinco pesos de cada cien.

Cuando el corte es por tamaño poblacional, el peso de las transferencias de otras jurisdicciones es más significativo a medida que decrece la escala poblacional del municipio. A la inversa sucede con el peso de los recursos propios: adquiere más relevancia en los municipios de mayor tamaño o en los grandes centros urbanos. En este recorte, tanto los impuestos como las regalías, poseen una incidencia insignificante, con la sola excepción del GBA (si se incluye en el mismo a la CABA) dada la importancia de los impuestos, de nivel provincial, que percibe la Ciudad Autónoma de Buenos Aires.

Vale recordar que el principal componente dentro de los recursos no propios corrientes viene dado por las transferencias que los municipios reciben en concepto de coparticipación provincial y regímenes conexos. La relevancia financiera de las transferencias no automáticas, corrientes, de origen provincial y nacional, es muy baja y generalmente tal tipo de recursos se vinculan a determinados programas sociales. En contraposición a ello, dentro de los recursos de capital, resulta preponderante el peso de las transferencias nacionales y provinciales, tanto automáticas (FFS) como no automáticas. La posibilidad de desagregar esas transferencias de capital no automáticas, resulta complejo de desarrollar, dada la poca información, apertura y disponibilidad de datos al respecto.

Ahora bien, resulta interesante observar la composición de la recaudación de las tasas, derechos y contribuciones, que constituyen más del $80 \%$ de los recursos corrientes propios de los municipios argentinos (el resto corresponde a impuestos, regalías y otros), según las diferentes regiones y escalas poblacionales, de modo tal de identificar los principales elementos y su importancia relativa. 
CUADRO NN 8

\section{COMPOSICIÓN DE LA RECAUDACIÓN DE TASA, DERECHOS Y CONTRIBUCIONES MUNICIPALES. AÑO 2013}

\begin{tabular}{lcccc}
\multicolumn{1}{c}{ REGIÓN } & SERVICIOS GENERALES & SEGURIDADE HIGIENE & RED VIAL MUNICIPAL & $\begin{array}{c}\text { OTRAS TASAS, DERECHOSY } \\
\text { CONTRIBUCIONES }\end{array}$ \\
\hline Municipios del GBA & $42 \%$ & $39 \%$ & $0 \%$ & $19 \%$ \\
Región Pampeana & $29 \%$ & $39 \%$ & $5 \%$ & $27 \%$ \\
Región Cuyo & $47 \%$ & $27 \%$ & $0 \%$ & $26 \%$ \\
Región NOA & $29 \%$ & $50 \%$ & $0 \%$ & $21 \%$ \\
Región NEA & $20 \%$ & $42 \%$ & $0 \%$ & $38 \%$ \\
Región Patagónica & $31 \%$ & $34 \%$ & $0 \%$ & $35 \%$ \\
Total Municipios & $34 \%$ & $39 \%$ & $3 \%$ & $24 \%$ \\
CABA & $64 \%$ & $1 \%$ & $0 \%$ & $35 \%$
\end{tabular}

FUENTE: ELABORACIÓN PROPIA SEGÚN INFORMACIÓN PROVENIENTE DE LOS MUNICIPIOS. NOTA: MUNICIPIOS DEL GBA Y TOTAL MUNICIPIOS NO INCLUYE CABA.

\begin{tabular}{lcccc}
\hline TAMAÑO & SERVICIOS GENERALES & SEGURIDAD E HIGIENE & RED VIAL MUNICIPAL & $\begin{array}{c}\text { OTRAS TASAS, DERECHOSY } \\
\text { CONTRIBUCIONES }\end{array}$ \\
\hline GBA & $47 \%$ & $29 \%$ & $0 \%$ & $23 \%$ \\
Top 5 & $31 \%$ & $53 \%$ & $0 \%$ & $16 \%$ \\
Aglomerados Grandes & $31 \%$ & $44 \%$ & $0 \%$ & $25 \%$ \\
Aglomerados Intermedios & $26 \%$ & $39 \%$ & $2 \%$ & $33 \%$ \\
Aglomerados Pequeños & $32 \%$ & $32 \%$ & $4 \%$ & $32 \%$ \\
Pueblos & $27 \%$ & $17 \%$ & $19 \%$ & $37 \%$
\end{tabular}

FUENTE: ELABORACIÓN PROPIA SEGÚN INFORMACIÓN PROVENIENTE DE LOS MUNICIPIOS. NOTA: GBA INCLUYE CABA.

Una primera observación indica que solamente dos tasas dan cuenta de un $60-80 \%$ de la recaudación total, salvo en los municipios de entre 2 mil y 50 mil habitantes, donde otras tasas, como las que se cobran por riego, servicios sanitarios y servicios asistenciales, tienen un peso relevante.

La tasa de servicios generales (TSG) comprende los cobros asociados a la prestación de los servicios de alumbrado público, barrido de calles, limpieza y conservación de la vía pública, así como también a la recolección, transporte, tratamiento y disposición final de los residuos sólidos domiciliarios, entre otros asuntos menores. Tiene mayor importancia en los municipios del Gran Buenos Aires, Cuyo y la CABA. El diverso comportamiento en la TSG obedece, en principio, a por lo menos cuatro variables: el grado de desarrollo urbano y económico de cada municipio, la elección del criterio de base imponible (metro lineal de frente o valuación fiscal), la escala de alícuotas y la eficacia en materia de recaudación.

Mejorar la eficacia recaudatoria es una prioridad de cara a incrementar la capacidad de financiamiento de los municipios para proveer a la población de más y mejores bienes y servicios públicos locales. En tal sentido, el aná- 


\section{GRÁFICO No 2COMPOSICIÓN DE LA RECAUDACIÓN DE TASAS, DERECHOS Y CONTRIBUCIONES EN LOS PRINCIPALES AGLOMERADOS URBANOS. AÑO 2013}

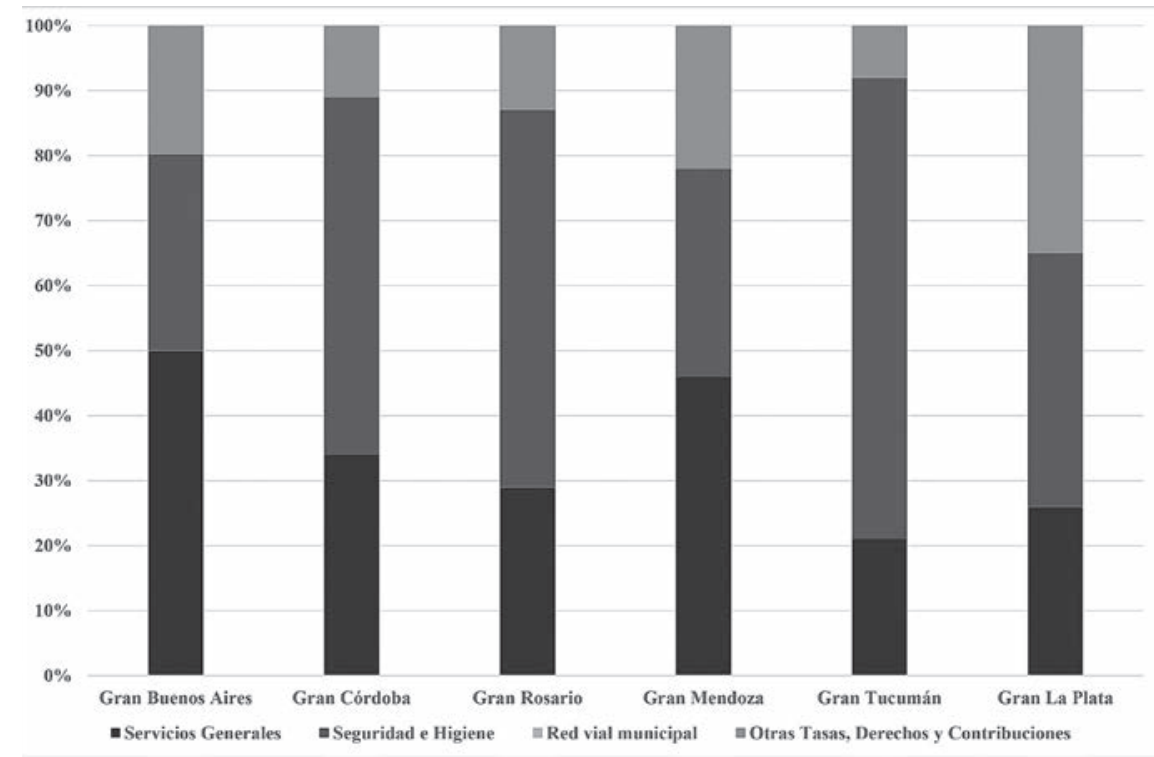

FUENTE: ELABORACIÓN PROPIA SEGÚN INFORMACIÓN PROVENIENTE DE LOS MUNICIPIOS. NOTA: GBA INCLUYE CABA.

lisis de los factores explicativos de los disimiles niveles de cobrabilidad que se verifican en el país, de los desafíos que esto entraña para la gestión municipal, y de los debates, propuestas y orientaciones de política en materia tributaria, no es posible expresarlo en pocas líneas, pero constituyen cuestiones de primer orden para el diagnóstico y desarrollo de los gobiernos municipales en el país.

La tasa por inspección de seguridad e higiene (TSeH) es un tributo que cobran los gobiernos locales en concepto de los servicios de inspección destinados a preservar la seguridad, salubridad e higiene en comercios, industrias y actividades de servicios o recreativas que se desarrollen en locales, establecimientos, oficinas o predios. Posee una alta relevancia en el NOA y NEA y en los dos aglomerados urbanos más importantes, decayendo su peso a medida que decrece el tamaño poblacional del municipio.

En los aglomerados urbanos de más de trescientos mil habitantes y en los municipios del GBA, la TSeH recauda entre cuatro y cinco de cada diez pesos de los recursos propios locales. En cambio, en la categoría de municipios más pequeños representa menos de dos de cada diez pesos. Al ser un gravamen asociado a la actividad comercial e industrial, su recaudación es mayor en aquellas ciudades donde estas actividades tienen mayor des- 
pliegue y magnitud. Por esa razón en los municipios metropolitanos y en las grandes ciudades del NOA, NEA y la región Pampeana la tasa posee un peso relevante. En el caso de la CABA, su insignificante peso, es producto de que allí opera un tributo provincial de características similares a la tasa, como es el impuesto a los ingresos brutos.

Por lo mencionado, no es sorprendente que no exista homogeneidad dentro de cada región geográfica, ya que el peso relativo de la citada tasa en la composición de los ingresos municipales tiene estrecha relación con la escala poblacional del municipio, y tiene menos importancia la localización del mismo.

La tasa de conservación y mantenimiento de la red vial municipal (CRVM) se cobra por la prestación de los servicios de conservación, reparación y mejorado de calles y caminos terciarios. Adquiere gran importancia para los municipios de menor escala poblacional, en particular, en aquellos ubicados en la provincia de Buenos Aires. De allí, que en la única región que posee alguna significancia es en la Pampeana. Va decreciendo su peso a medida que aumenta el tamaño poblacional, siendo inexistente en los grandes aglomerados urbanos.

En el componente "Otras tasas, derechos y contribuciones" se encuentra una muy diversa cantidad de tributos que forman parte de los recursos de origen municipal, que en el promedio de los municipios del país totalizan un valor nada despreciable y engloban a servicios sanitarios, habilitaciones comerciales, seguridad ciudadana, derechos de publicidad y propaganda, construcción, espectáculos públicos, cementerio y oficina, entre otros.

En general, en las tasas, es habitual que no se tenga en cuenta (o se considere en forma muy indirecta o marginal) el costo del servicio individualmente recibido y se cobre a cada contribuyente en razón de su capacidad de pago (por ejemplo al tomar la valuación fiscal como base imponible de la tasa de servicios generales) o de su escala económica, cuando se considera el nivel de facturación de las personas físicas o jurídicas para determinar la tasa por inspección de seguridad e higiene (Macon, 2000).

Respecto al principio más amplio de que el monto total cobrado por cada tasa debe ser similar al costo del servicio que la misma pretende financiar, tampoco se cumple en la práctica, como ocurre en el caso de las dos principales tasas (servicios generales y seguridad e higiene), debido a que lo que suele cobrarse a los hogares no es poco habitual que resulte insuficiente para solventar los servicios de alumbrado, barrido y limpieza (a veces ni 
siquiera alcanza para cubrir la recolección de los residuos sólidos urbanos o el alumbrado público), y lo que se extrae de la actividad económica en concepto de tasa por inspección de seguridad e higiene es regla que exceda largamente el gasto municipal por tal servicio.

\section{E L G A S T O P Ú B L I C O M U N I C I P A L}

En 2013, en el total del país el gasto público municipal se componía de un $84 \%$ de gasto corriente y un $16 \%$ de gasto de capital. En relación al gasto corriente, en primer lugar, interesa conocer cuál es el peso que en los presupuestos municipales corresponde a los salarios de los trabajadores. Una extrema concentración en este tipo de erogación daría cuenta de una alta rigidez presupuestaria. En promedio el 57\% se destinaba a salarios, como se puede apreciar en los siguientes cuadros:

En términos dinámicos, tanto el peso del gasto de capital en el gasto total $(16 \%)$, como del gasto en personal en el gasto corriente $(57 \%)$, para el conjunto de los municipios del país, no ha sufrido grandes oscilaciones en las dos últimas décadas, más allá de una fuerte disminución (y recuperación posterior) como consecuencia de la crisis de 2001, según surge de los datos que publica la Dirección Nacional de Coordinación Fiscal con las Provincias del Ministerio de Economía y Finanzas Públicas de la Nación, y que se remontan a 1993.

En relación al gasto en personal, en los municipios del GBA y la CABA es donde se presenta el guarismo más bajo, siendo casi diez puntos porcentuales menos que la media nacional. En las regiones de la Patagonia, NEA y NOA casi dos tercios del gasto corriente se destinan a salarios. Respecto al análisis por escala, el peso del gasto en personal resulta algo más bajo en los aglomerados de más de 700.000 habitantes y en los municipios bonaerenses que integran el GBA.

En relación a la inversión pública, identificada con los gastos de capital, y apreciada por su capacidad para transformar el territorio y mejorar las condiciones de vida de las comunidades, en el total del país el guarismo alcanza el $16 \%$ del gasto total. Se destacan por encima de esa cifra, los municipios del NOA y NEA.

Cuando el análisis es por corte poblacional, en casi todas las categorías el valor oscila entre el 16\%-19\%, salvo en los aglomerados urbanos de entre 


\section{GRÁFICO NN 3}

COMPOSICIÓN DEL GASTO MUNICIPAL. PESO DEL GASTO EN PERSONAL EN EL GASTO CORRIENTE Y DEL GASTO DE CAPITAL EN EL TOTAL, POR REGIÓN Y TAMAÑO. AÑO 2013

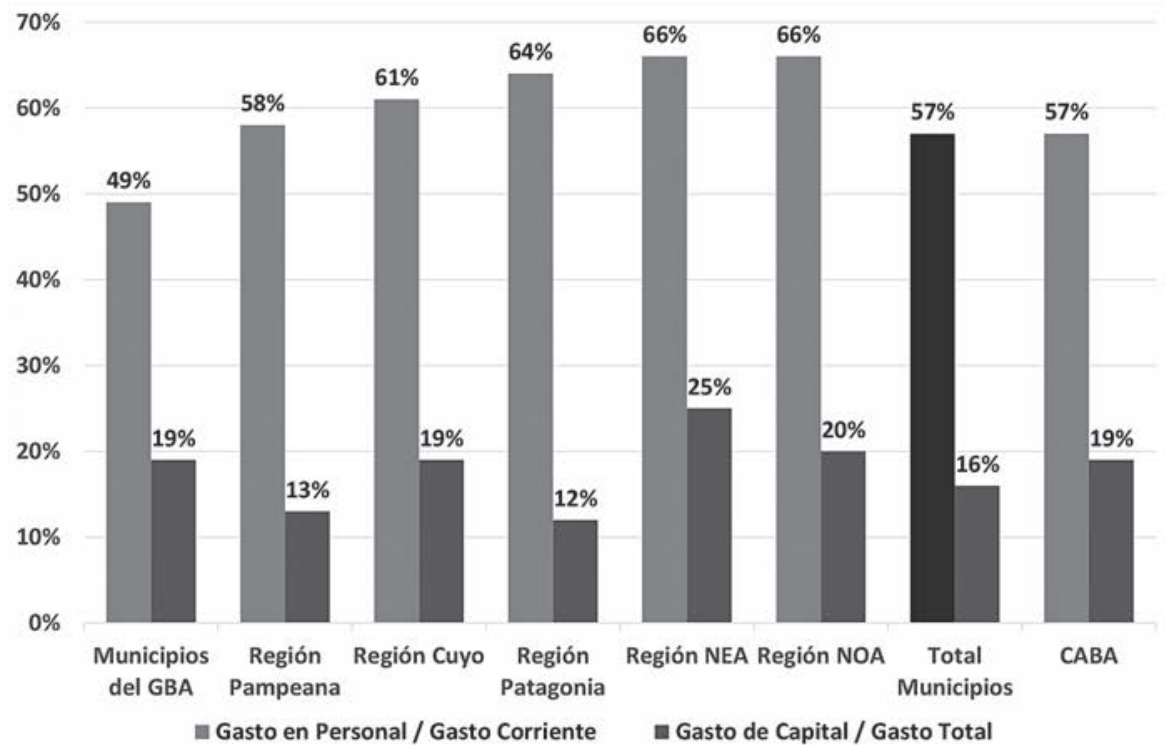

FUENTE: ELABORACIÓN PROPIA SEGÚN INFORMACIÓN PROVENIENTE DE LOS MUNICIPIOS. NOTA: MUNICIPIOS DEL GBA Y TOTAL MUNICIPIOS NO INCLUYE CABA

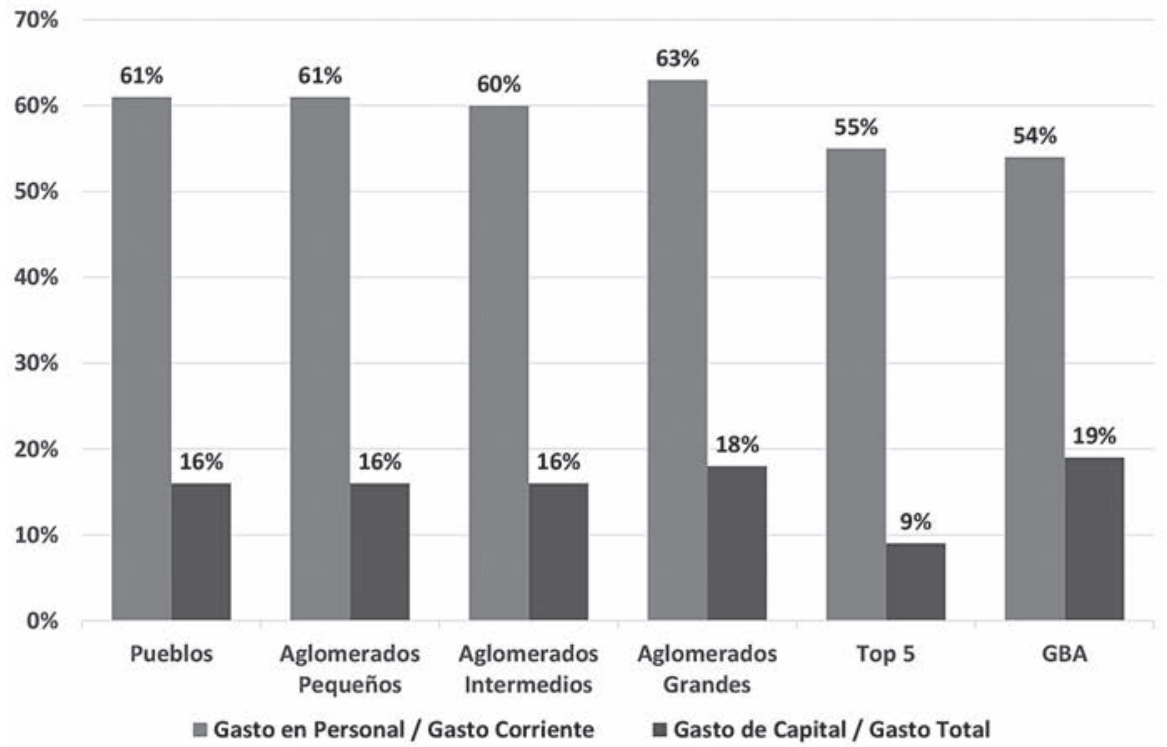

FUENTE: ELABORACIÓN PROPIA SEGÚN INFORMACIÓN PROVENIENTE DE LOS MUNICIPIOS. NOTA: GBA INCLUYE CABA. 
setecientos mil y un millón y medio de habitantes del interior del país que destinan solamente el $9 \%$ del gasto total a la inversión pública.

Respecto al gasto municipal por finalidad y función, los datos disponibles del Ministerio de Economía y Finanzas Públicas de la Nación, que refieren al conjunto de municipios del país, corresponden al período 1980-2009. Atento a ello, no es posible dar cuenta acabadamente de lo acaecido en el último lustro, ni conocer o analizar la situación por región y escala poblacional.

No obstante, resulta de interés señalar que en el año 1980 los municipios argentinos destinaban más de un $85 \%$ de sus esfuerzos a cuatro funciones: un $38 \%$ de sus gastos a administración general, un $34 \%$ a servicios urbanos (recolección y disposición de residuos, alumbrado público, limpieza y mantenimiento de calles y espacios verdes, entre otros), un $8 \%$ a salud y un $6 \%$ a promoción y asistencia social. En 2009, si bien las mismas cuatro funciones seguían concentrando casi un $90 \%$ de los recursos municipales, su composición había variado significativamente. Así, las funciones más tradicionales, vinculadas con la labor administrativa (31\%) y con los servicios urbanos $(24 \%)$ habían perdido peso, a manos de un mayor desarrollo de servicios sociales, tanto salud $(11 \%)$ como promoción y asistencia social (22\%), lo que da cuenta de un creciente rol de los gobiernos municipales en el fomento al desarrollo comunitario y local.

Dentro del gasto corriente, interesa observar, por su importancia, lo que ocurre con dos funciones claves: la recolección de residuos domiciliarios y el alumbrado público. En ambos casos constituyen actividades directamente relacionadas con la tasa de servicios generales (o alumbrado, barrido y limpieza). 


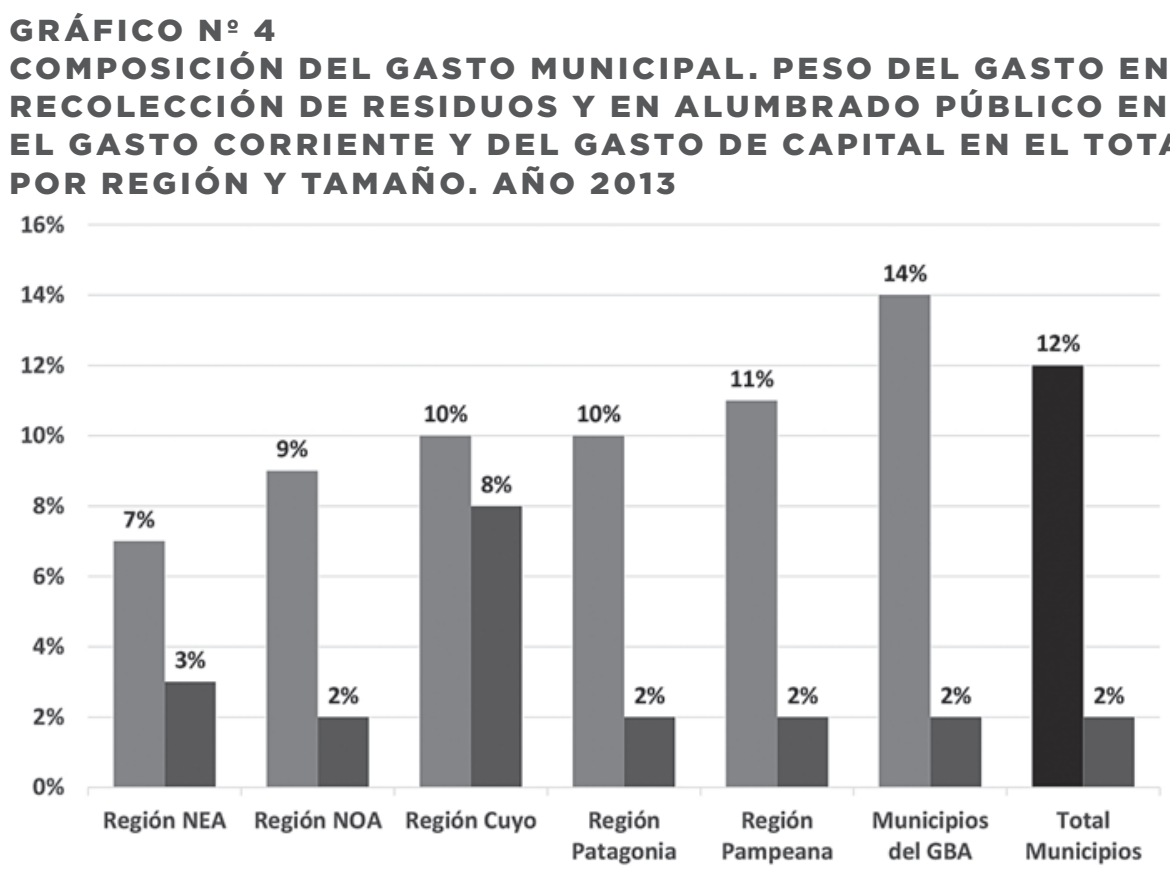

[ Gasto en Recoleccción de Residuos / Gasto Corriente a Gasto de en Alumbrado Público / Gasto Corriente FUENTE: ELABORACIÓN PROPIA SEGÚN INFORMACIÓN PROVENIENTE DE LOS MUNICIPIOS. NOTA: MUNICIPIOS DEL GBA Y TOTAL MUNICIPIOS NO INCLUYE CABA.

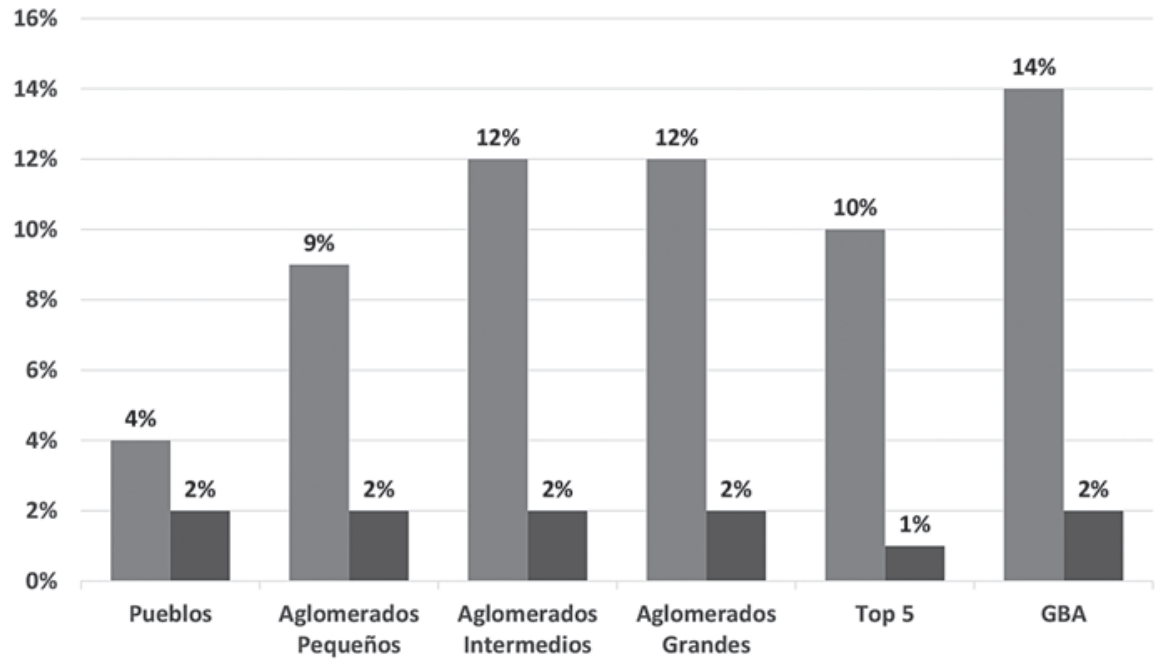

n Gasto en Recoleccción de Residuos / Gasto Corriente a Gasto de en Alumbrado Público / Gasto Corriente

FUENTE: ELABORACIÓN PROPIA SEGÚN INFORMACIÓN PROVENIENTE DE LOS MUNICIPIOS. NOTA: GBA NO INCLUYE CABA, DADA LA NO DISPONIBILIDAD DE LOS RESPECTIVOS DATOS DE DICHA JURISDICCIÓN 
Puede apreciarse que particularmente en el GBA, el costo de los servicios de limpieza urbana, son particularmente importantes en los presupuestos municipales, ya que ocupan el $14 \%$ del gasto corriente. En cambio, el gasto en alumbrado público, en casi todas las regiones del país (excepto Cuyo) y en todos los tamaños poblaciones, representa entre 1\%-3\% del gasto corriente.

A su vez, dentro del gasto de capital, es interesante conocer la incidencia del Fondo Federal Solidario (FFS) en el sostenimiento de la inversión transformadora en el ámbito territorial. La importancia del FFS viene dada por el hecho de que se trata de la única transferencia de capital automática que reciben la totalidad de los municipios argentinos. A la vez que juega un rol relevante en el financiamiento de la inversión pública local, en tanto es el único recurso de tipo recurrente, que permite por su carácter afectado, establecer un piso para dicho tipo de erogación. Dado que los municipios, como ya se ha mencionado, reciben un $9 \%$ del total de la recaudación nacional por exportaciones de soja, el monto a percibir depende del volumen y precio de dichas exportaciones por lo que su crecimiento nominal año a año seguirá las fluctuaciones dichas variables.

En promedio, el FFS financia un $12 \%$ de la inversión pública municipal, sin embargo el porcentaje de cobertura presenta contrastes cuando se lo evalúa en términos geográficos. Se destaca el carácter federal del Fondo, ya que contribuye a financiar una mayor parte de las erogaciones de capital en los municipios ubicados en las regiones más postergadas en términos de desarrollo económico, como ocurre en el NOA y Cuyo.

Respecto a la contribución por tamaño de municipio, se puede afirmar que el FFS cubre un séptimo del gasto de capital en los municipios que no son del GBA. A su vez, estas dos condiciones se retroalimentan, lo que se verifica, por ejemplo, en el hecho de que el FFS sostiene a cerca de un cuarto de la inversión pública municipal de los distritos con entre dos mil y cincuenta mil habitantes ubicados en Cuyo, NOA y NEA. 


\section{GRÁFICO No 5}

FONDO FEDERAL SOLIDARIO COMO PORCENTAJE DEL GASTO DE CAPITAL TOTAL, POR REGIÓN Y TAMAÑO. AÑO 2013

$35 \%$

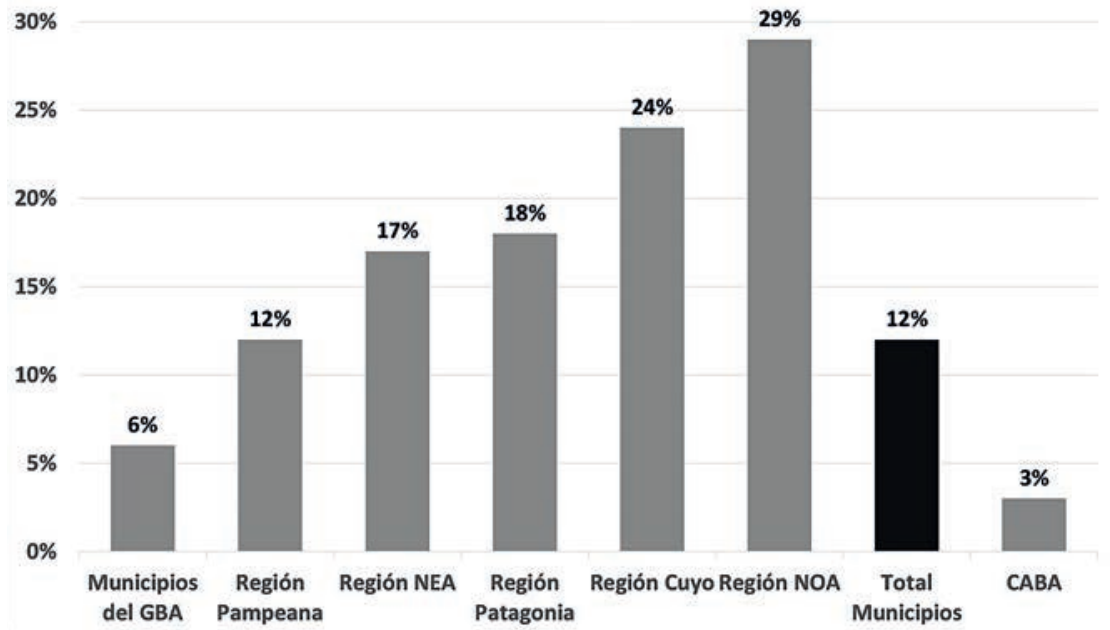

FUENTE: ELABORACIÓN PROPIA SEGÚN INFORMACIÓN PROVENIENTE DE LOS MUNICIPIOS. NOTA: MUNICIPIOS DEL GBA Y TOTAL MUNICIPIOS NO INCLUYE CABA.

$25 \%$

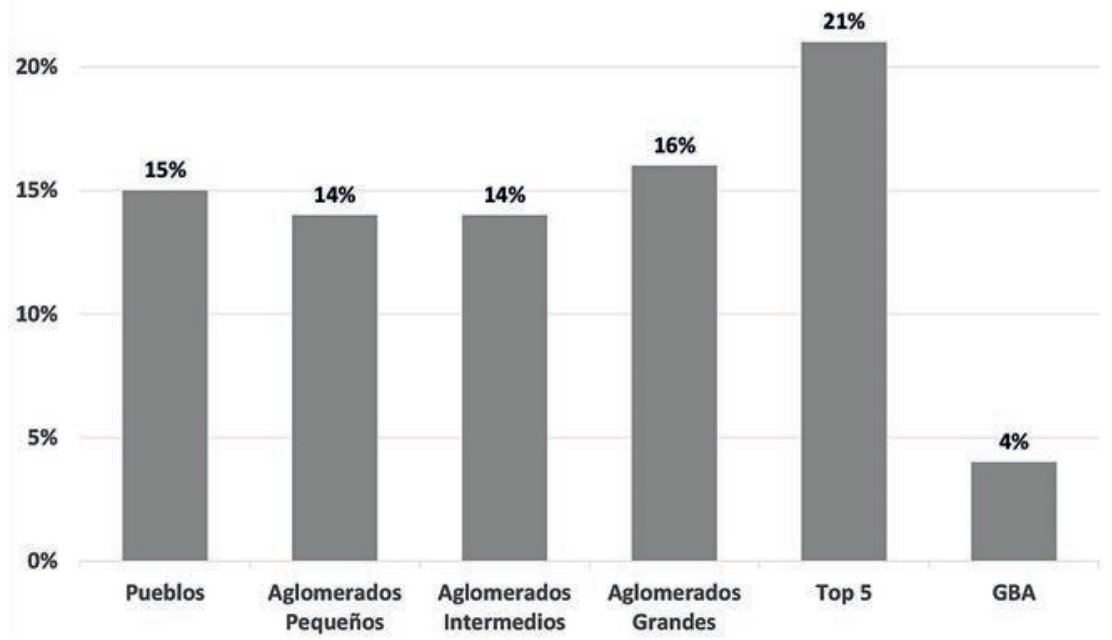

FUENTE: ELABORACIÓN PROPIA SEGÚN INFORMACIÓN PROVENIENTE DE LOS MUNICIPIOS. NOTA: GBA INCLUYE CABA. 


\section{L A C OMPARACIÓN DEL G A S T O P ÚB I C O \\ MUNICIPAL PER CÁPITA DE ARGENTINA \\ CONOTRASCIUDADESLATINOAMER I CANAS}

Una buena forma de analizar el alcance de la intervención de los estados locales argentinos, es comparar el gasto público municipal per cápita de Argentina con otras ciudades latinoamericanas (Porto, 2004). Para ello, se seleccionaron algunos aglomerados urbanos argentinos y de Brasil y Colombia, cuya información se puede apreciar en el siguiente cuadro:

\section{CUADRO Nㅇ 9 \\ COMPOSICIÓN DE LA RECAUDACIÓN DE TASA, DERECHOS Y CONTRIBUCIONES MUNICIPALES. AÑO 2013}

$\begin{array}{lcc}\text { MUNICIPIOS } & \text { AÑO DE INFORMACIÓN } & \text { GASTO PER CÁPITA EN U\$S } \\ \text { Río de Janeiro (BR) } & 2011 & 1262 \\ \text { San Paulo (BR) } & 2011 & 811 \\ \text { Porto Alegre (BR) } & 2011 & 995 \\ \text { Recife (BR) } & 2011 & 670 \\ \text { Brasil (media nacional) } & 2011 & 705 \\ \text { Medellín (CO) } & 2012 & 929 \\ \text { Bogotá (CO) } & 2012 & 792 \\ \text { Colombia (media nacional) } & 2012 & 628 \\ \text { Gran Rosario (ARG) (1) } & 2013 & 705 \\ \text { Gran Córdoba (ARG) (2) } & 2013 & 666 \\ \text { Gran La Plata (ARG) (3) } & 2013 & 461 \\ \text { Gran Mendoza (ARG) (4) } & 2013 & 451 \\ \text { Gran Tucumán (ARG) (5) } & 2013 & 421 \\ \text { Gran Buenos Aires (sin (ABA) (6) } & 2013 & 401 \\ \text { Argentina (media nacional) } & 2013 & 513 \\ & & \end{array}$

FUENTE: ELABORACIÓN PROPIA EN BASE A DATOS DE MUNICIPIOS ARGENTINOS, IPEADATA EN BASE A DATOS DEL MINISTERIO DE FAZENDA DE BRASIL Y WWW.SIELOCAL.COM (COLOMBIA). NOTA: (1) GRAN ROSARIO: INCLUYE LOS MUNICIPIOS DE ROSARIO Y SAN LORENZO. (2) GRAN CÓRDOBA: INCLUYE LOS MUNICIPIOS DE CÓRDOBA, VILLA ALLENDE Y UNQUILLO. (3) GRAN LA PLATA: INCLUYE LOS MUNICIPIOS DE LA PLATA, ENSENADA Y BERISSO. (4) GRAN MENDOZA: INCLUYE LOS MUNICIPIOS DE MENDOZA, GODOY CRUZ, LUJÁN DE CUYO Y LAS HERAS. (5) GRAN TUCUMÁN: INCLUYE SOLAMENTE EL MUNICIPIO DE SAN MIGUEL DE TUCUMÁN. (6) GRAN BUENOS AIRES: INCLUYE LOS 24 MUNICIPIOS DEL CONURBANO BONAERENSE, A SABER: TIGRE, FLORENCIO VARELA, LOMAS DE ZAMORA, AVELLANEDA, LA MATANZA, BERAZATEGUI, EZEIZA, SAN ISIDRO, ALMIRANTE BROWN, ESTEBAN ECHEVERRÍA, GRAL. SAN MARTIN, LANÚS, MALVINAS ARGENTINAS, MERLO, MORENO, MORÓN, QUILMES, TRES DE FEBRERO, SAN MIGUEL, JOSÉ C. PAZ, SAN FERNANDO, HURLINGHAM, ITUZAINGÓ Y VICENTE LÓPEZ.

Aún con la diferencia en el año para el que se cuenta con la información, los datos son reveladores. El gasto público per cápita en la media nacional de los municipios argentinos es un $22 \%$ inferior a los de sus pares colombianos y un $37 \%$ más bajo que sus homónimos brasileños. Sólo, Gran Córdoba supera a la media nacional de Colombia o se acerca a los valores de algunas de las otras ciudades (Recife).

Incluso, esa zona mediterránea argentina se destaca porque el guarismo supera entre un $44 \%$ y un $66 \%$ al resto de los aglomerados argentinos. En el resto de los casos, el valor per cápita es muy inferior a lo observado en otros 
grandes aglomerados latinoamericanos. En una zona de profunda disparidad en términos de desarrollo económico y social, como es el Gran Buenos Aires (concentra el 24,72\% de la población total argentina) el valor es el más bajo de todas las referencias e inclusive un $27,9 \%$ inferior a la media nacional argentina.

\section{LA AUTONOMÍA FINANCIERA, EL AUTOFINANCIAMIENTOY ELRESULTADO F I N A N C I E R O}

Un indicador de suma utilidad para apreciar la situación fiscal de los municipios argentinos es la "autonomía financiera". Ella refiere a la proporción de los recursos corrientes de los municipios que corresponden a fondos de recaudación propia. En estos se incluyen a las tasas, derechos y contribuciones, así como también los impuestos de jurisdicción municipal y las regalías directamente percibidas por los municipios. Aquí, se incorporan además otros recursos propios, como los provenientes de rentas de la propiedad, ingresos de operación, venta de bienes y servicios y cobro de multas y cánones, entre otros. Metodológicamente, no se consideran los recursos de capital, debido al carácter no permanente que los mismos suelen exhibir, y además, porque pueden producir notables desvíos en determinados años, en especial cuando corresponden a recursos que financian obras de alto impacto económico.

En el promedio del país, los municipios recaudan menos de la mitad de los recursos corrientes con los que cuentan. Las regiones de Cuyo, NEA y NOA presentan guarismos muy por debajo de la media. En cambio, los municipios del GBA, la región pampeana y patagónica se ubican en torno al 47\%-49\%. Como se ha mencionada, la CABA, presenta un elevadísimo nivel de autonomía financiera.

Cuando el corte es por el tamaño poblacional, son los municipios más pequeños los que presentan las peores cifras, demostrando un alto nivel de dependencia de los recursos de otras jurisdicciones. En cambio, con la excepción de los aglomerados urbanos de entre trescientos y setecientos mil habitantes, aquellas ciudades de mayor escala poblacional muestran los mejores indicadores, llegando incluso los grandes aglomerados del interior del país a financiar casi seis de cada diez pesos de sus ingresos fiscales totales.

Por último, el indicador de "resultado financiero" (Capello, Diarte y Freille, 2013), mide la relación entre el conjunto de recursos propios municipales 
GRÁFICO No 6

AUTONOMÍA FINANCIERA. RECURSOS CORRIENTES PROPIOS EN PORCENTAJE DE LOS RECURSOS CORRIENTES TOTALES, POR REGIÓN Y TAMAÑO. AÑO 2013

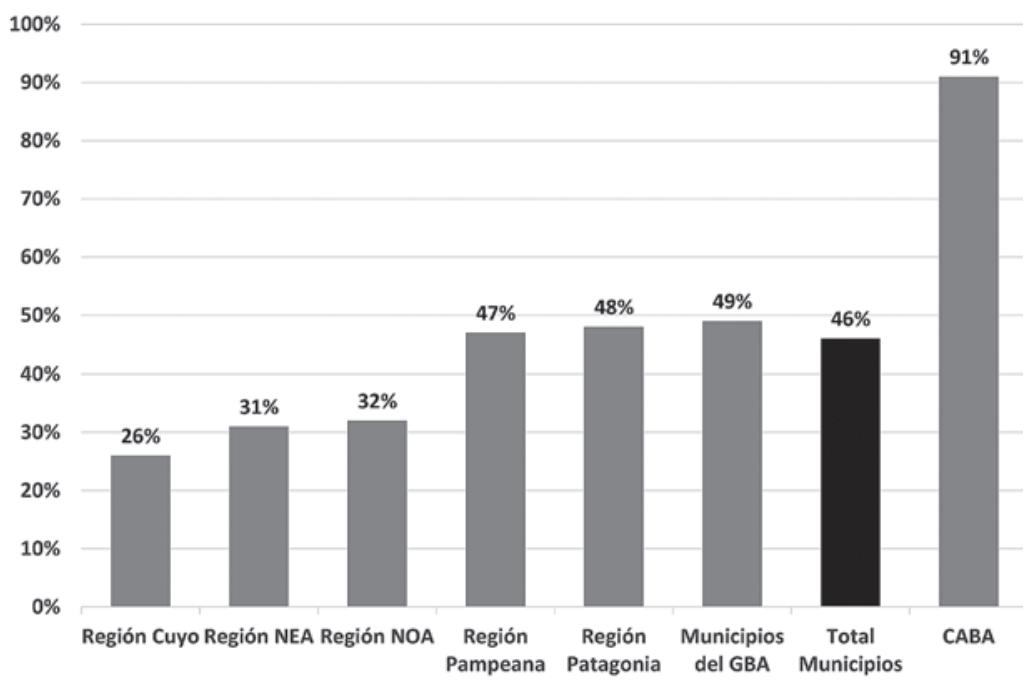

FUENTE: ELABORACIÓN PROPIA SEGÚN INFORMACIÓN PROVENIENTE DE LOS MUNICIPIOS. NOTA: MUNICIPIOS DEL GBA Y TOTAL MUNICIPIOS NO INCLUYE CABA

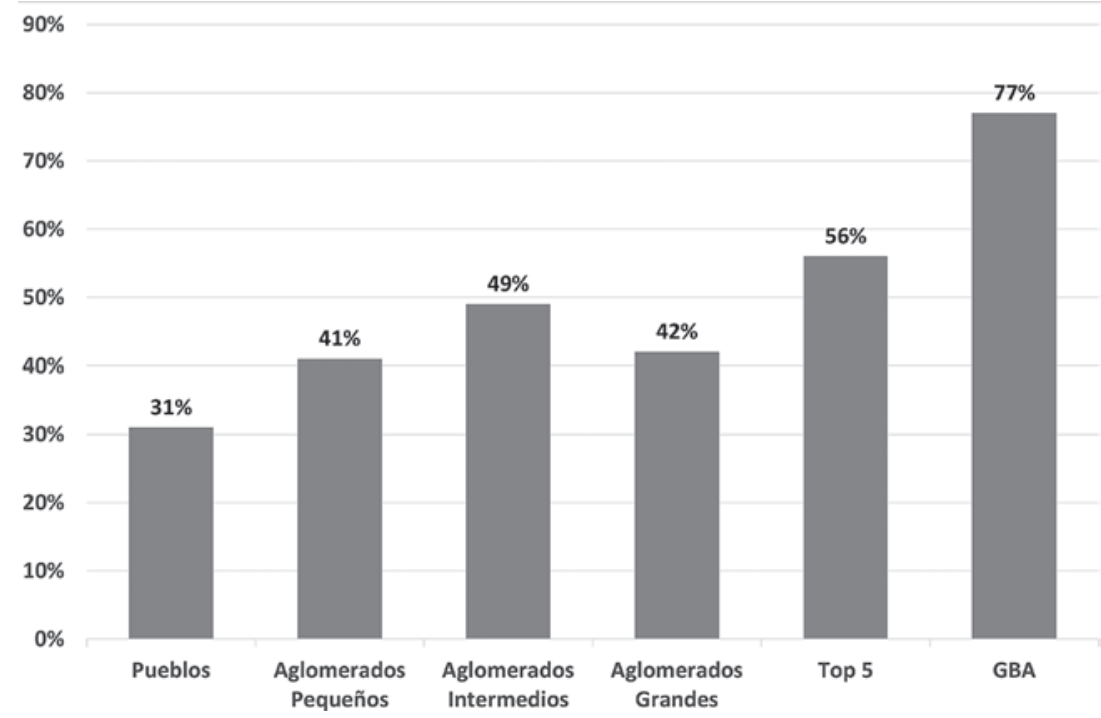

FUENTE: ELABORACIÓN PROPIA SEGÚN INFORMACIÓN PROVENIENTE DE LOS MUNICIPIOS. NOTA: GBA INCLUYE CABA. 
(propios y por transferencias corrientes y de capital) y las erogaciones (corrientes y de capital).

\section{CUADRO N 10 \\ RESULTADO FINANCIERO MUNICIPAL COMO PORCENTAJE DEL GASTO TOTAL. AÑO 2013}

\begin{tabular}{lc|}
\hline \multicolumn{1}{|c}{ REGIÓN } & $\begin{array}{c}\text { RESULTADO FINANCIERO / } \\
\text { GASTO TOTAL }\end{array}$ \\
\hline Municipios del GBA & $4 \%$ \\
Región Cuyo & $-2 \%$ \\
Región NEA & $1 \%$ \\
Región NOA & $1 \%$ \\
Región Pampeana & $-1 \%$ \\
Región Patagónica & $0 \%$ \\
Total País & $1 \%$ \\
CABA & $-2 \%$ \\
\end{tabular}

FUENTE: ELABORACIÓN PROPIA SEGÚN INFORMACIÓN PROVENIENTE DE LOS MUNICIPIOS. NOTA: MUNICIPIOS DEL GBA Y TOTAL MUNICIPIOS NO INCLUYE CABA.

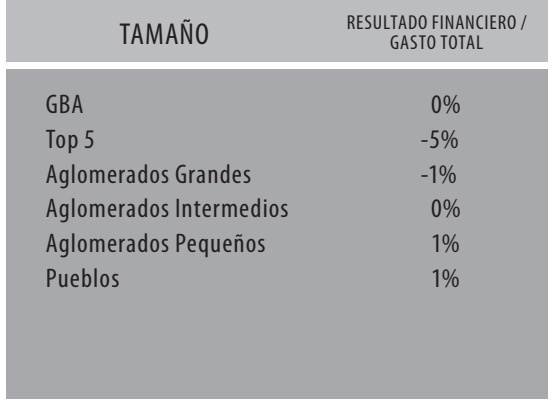

FUENTE: ELABORACIÓN PROPIA SEGÚN INFORMACIÓN PROVENIENTE DE LOS MUNICIPIOS. NOTA: GBA INCLUYE CABA.

Se advierte una situación global con un leve superávit financiero, para el conjunto de municipios que integran la muestra. Así, a nivel regional las situaciones observadas son de pequeños déficits y superávits. Entre los resultados financieros positivos se destacan los municipios del GBA y aquellos que oscilan entre una escala poblacional entre intermedia y menor. Entre los que presentan déficits, las situaciones más preocupantes corresponden a los grandes aglomerados urbanos, a Cuyo y la Ciudad Autónoma de Buenos Aires. En cuanto al resultado primario (antes del pago de servicios e intereses de deuda), éste se ubica cerca del $1 \%$ de las erogaciones corrientes.

En fin, los municipios pequeños poseen menor autonomía fiscal, pero terminan siendo los que mejores resultados financieros presentan en todas las regiones, mientras que los medianos y grandes, salvo los del Gran Buenos Aires, se ven mayores déficits. Esto brinda un panorama acerca del sesgo que posee el sistema de transferencias interjurisdiccionales (coparticipación de impuestos), desde los gobiernos provinciales hacia los municipales. Vale recordar que dicho sesgo surge como consecuencia de la adopción de criterios de distribución que contemplan parámetros tales como partes iguales o superficie, beneficiando a los distritos menos poblados. 


\section{C O N C L U S I O N E S}

En nuestro país, el gasto consolidado municipal representa el 3,7\% del PBI, mientas que los ingresos apenas alcanzan el 1,3\% del PBI. Esto demuestra la incapacidad de los municipios argentinos para mantener sus funciones mediante sus propios recursos, y en contraposición, el nivel de dependencia que poseen de los aportes (coparticipación y transferencias específicas) realizados desde los otros niveles del Estado, que representan más de la mitad de los recursos con los que cuentan. Además, por las enormes diferencias y características de los gobiernos locales argentinos, se verifica una marcada heterogeneidad en materia fiscal entre las distintas ciudades (Caplan de Cohen, 2000), tanto en las regiones geográficas, como por el tamaño poblacional.

Entre un $60 \%$ y $80 \%$ de la recaudación propia de los municipios proviene de las tasas, derechos y contribuciones, de allí la importancia de estos tipos de instrumentos fiscales, aunque la distinción conceptual entre tasa e impuesto, ha sido desvirtuada en la práctica real. Dos tasas (servicios generales e inspección de seguridad e higiene), en el año 2013, representaron el 73\% de la recaudación total de tasas, derechos y contribuciones, lo que demuestra la fuerte concentración recaudatoria existente. Pero, a su vez, conviven una enorme proliferación de tasas, derechos, contribuciones e impuestos que se combinan de múltiples formas y que hacen muy difícil encarar el diagnóstico y la mejora en la recaudación municipal desde una perspectiva global.

Las tasas de servicios generales y por inspección de seguridad e higiene no terminan de tener en cuenta en forma directa el costo del servicio individualmente recibido y se cobran a cada contribuyente, en buena medida, en proporción a su capacidad de pago (en la TSG al considerar la valuación fiscal como base imponible) o de su escala económica (cuando se considera el nivel de facturación de las personas físicas o jurídicas para determinar el valor del monto a abonar en concepto de tasa por inspección de seguridad e higiene).

Frente a un aumento de las funciones y las demandas ciudadanas y con la existencia de limitaciones en la mayoría de las legislaciones provinciales para el cobro de impuestos por parte de los municipios, las tasas, en la práctica, operan como una imposición a determinadas actividades, que los municipios explotan buscando algo que podríamos denominar "especialización funcional". En aquellos casos donde hay predominancia de una actividad económica, el peso de la tasa por inspección de seguridad e higiene, es la que tracciona la mayor cantidad de recursos para las arcas municipales. Algo similar ocurre en los municipios con caracte- 
rísticas rurales, con la tasa para la conservación de la red vial municipal.

Un municipio moderno, con atribuciones y responsabilidades acordes a los procesos de descentralización ocurridos en las últimas décadas (Asensio, 2006) y que pueda acompañar el desarrollo de políticas de participación ciudadana que complementan a la democracia representativa, no puede estar limitado a un sistema de recaudación basado en el concepto tradicional de tasa. Al mismo tiempo no resulta conveniente sostener un entramado institucional basado en tal instrumento y que, en la práctica, ha sido completamente desvirtuado en la mayoría de los municipios, al menos claramente en los de mayor población.

El hecho de que en los municipios de mayor tamaño aumente la participación de la tasa por inspección de seguridad e higiene en la recaudación total, si bien puede ser un elemento auspicioso desde el punto de vista de la disponibilidad financiera, no resulta aconsejable en términos de la progresividad tributaria, ya que por sus características, se trata de una tasa trasladable al precio de los productos que terminando pagando los consumidores. En ese sentido, los aumentos de la recaudación basados en el valor de la propiedad como hecho imponible son menos trasladables y pueden ser objeto de una progresividad tributaria mucho más sencilla, más aun cuando se trabaja con alícuotas crecientes según el valor del bien.

En materia de gasto público per cápita, a la luz de lo que ocurre con otras ciudades latinoamericanas, los valores alcanzados en Argentina, resultan bajos, teniendo en cuenta el nivel de desarrollo relativo. El gasto en personal y en servicios urbanos (recolección de residuos y alumbrado público) alcanza una magnitud, en la media nacional, superior al 70\% de los gastos corrientes, dejando poco margen de maniobra e intervención en otras áreas importantes de la gestión pública local.

Con relación al gasto de capital, el aporte realizado por el Estado nacional a través del Fondo Federal Solidario (única transferencia automática y condicionada al financiamiento de inversión pública municipal) posee un nivel relevante en las regiones más postergadas del país. Por último, en general, el resultado financiero de los municipios argentinos presenta una situación equilibrada.

En definitiva, la política fiscal municipal debe lograr una mayor eficiencia y eficacia en la recaudación de los tributos municipales. Todo esto debe ir acompañado de reformas provinciales que doten a los municipios de un más amplio espacio de intervención fiscal que permita reducir su de- 
pendencia de las transferencias de otras jurisdicciones, para con todo ello, obtener una provisión pública local de bienes y servicios, con un piso de homogeneidad en términos de calidad, cantidad y accesibilidad, en todo el territorio nacional.

\section{A NEX O METO D O L Ó G I C O}

La selección abarcó a un total de 277 municipios con un umbral mínimo de población de 2.000 habitantes. Para definir a las regiones geográficas, los municipios se agruparon según el siguiente criterio:

- Región Pampeana: municipios de la provincia de Buenos Aires (excluidos los del Gran Buenos Aires), y a distritos de Córdoba, Entre Ríos, La Pampa y Santa Fe.

- Región Cuyo: incluye a municipios de las provincias de Mendoza, San Juan y San Luis.

- Región NOA: incluye a municipios de las provincias de Catamarca, La Rioja, Jujuy, Salta, Santiago del Estero y Tucumán.

- Región NEA: incluye a municipios de las provincias de Corrientes, Chaco, Formosa y Misiones.

- Región Patagónica: incluye a municipios de las provincias de Neuquén, Río Negro, Chubut, Santa Cruz y Tierra del Fuego.

Se clasificó a los municipios en:

- Municipios del Gran Buenos Aires: incluye los 24 municipios de la provincia de Buenos Aires que integran el AMBA.

- Aglomerado de más de 700 mil y menos de 1,5 millones de habitantes: incluye a municipios que forman parte de un aglomerado urbano con esa escala poblacional.

- Aglomerado de más de 300 mil y menos de 700 mil habitantes: incluye a municipios que forman parte de un aglomerado urbano con esa escala poblacional.

- Municipios entre 100 y 300 mil habitantes: aquellos cuya escala de población se encuentra en ese rango.

- Municipios entre 50 y 100 mil habitantes: aquellos cuya escala de población se encuentra entre esos valores.

- Municipios entre 2 y 50 mil habitantes: aquellos cuya escala de población se encuentra en ese rango.

Con el fin de dar cuenta de la representatividad del trabajo, se detallan en base a la clasificación descripta y por región geográfica los municipios se- 
leccionados cuyos datos e información forman parte del presente estudio:

\section{Municipios del Conurbano (24)}

Tigre, Florencio Varela, Lomas de Zamora, Avellaneda, La Matanza, Berazategui, Ezeiza, San Isidro, Almirante Brown, Esteban Echeverría, Gral. San Martin, Lanús, Malvinas Argentinas, Merlo, Moreno, Morón, Quilmes, Tres de Febrero, San Miguel, José C. Paz, San Fernando, Hurlingham, Ituzaingó y Vicente López.

Municipios de Aglomerados Urbanos de entre 700.000 y 1.500.000 Habitantes (13)

Región Pampeana (8): Córdoba, Rosario, Unquillo, Villa Allende, San Lorenzo, La Plata, Berisso y Ensenada.

Región Cuyo (4): Las Heras y Mendoza, Godoy Cruz y Luján de Cuyo.

Región NOA (1): San Miguel de Tucumán.

Municipios de Aglomerados Urbanos de entre 300.000 y 700.000 habitantes (20)

Región Pampeana (4): Santa Fe, Recreo, Bahía Blanca y General Pueyrredón. Región Cuyo (5): Pocito, Rawson, San Juan, Rivadavia y Santa Lucía.

Región NOA (4): Salta, Santiago del Estero, San Salvador de Jujuy y Palpalá. Región NEA (5): Corrientes, Posadas, Resistencia, Fontana y Puerto Vilelas. Patagonia (2): Neuquén y Cipolletti.

Municipios de entre $\mathbf{1 0 0 . 0 0 0}$ y $\mathbf{3 0 0 . 0 0 0}$ habitantes (20)

Región Pampeana (12): San Nicolás de los Arroyos, Tandil, Pergamino, Rio Cuarto, Concordia, Paraná, Santa Rosa, Pilar, Escobar, Luján, Olavarría y Zárate.

Región Cuyo (3): San Martín, San Rafael y San Luis.

Región NOA (2): San Fernando del Valle de Catamarca y La Rioja.

Región NEA (1): Formosa.

Región Patagonia (2): Comodoro Rivadavia y San Carlos de Bariloche.

Municipios de entre 50.000 y 100.000 habitantes (29)

Región Pampeana (23): Chivilcoy, Azul, General Rodríguez, Necochea, Cañuelas, Villa Carlos Paz, Villa Maria, Gualeguaychú, Concepción del Uruguay, Reconquista, Venado Tuerto, Rafaela, General Pico, Junín, Coronel Rosales, Campana, La Costa, Marcos Paz, Mercedes, Presidente Perón, San Pedro, San Vicente y Tres Arroyos.

Región NOA (1): Orán.

Región NEA (3): Goya, Clorinda y Oberá.

Región Patagonia (2): General Roca y Ushuaia. 


\section{Municipios de entre 2.000 y $\mathbf{5 0 . 0 0 0}$ habitantes (171)}

Región Pampeana (121): Lincoln, Lobos, Pehuajó, Carlos Casares, Carlos Tejedor, Patagones, General Belgrano, General Madariaga, Lobería, Mar Chiquita, Pinamar, Rivadavia, San Antonio de Areco, Castelli, Florentino Ameghino, Punta Indio, Tapalqué, Tres Lomas, General Pinto, Guamini, Laprida, Pila, Monte Hermoso, Adolfo Alsina, Adolfo Gonzales Chaves, Alberti, Arrecifes, Ayacucho, Balcarce, Baradero, Benito Juárez, Bolívar, Bragado, Brandsen, Capitán Sarmiento, Carmen de Areco, Chacabuco, Chascomús, Colón, Coronel Dorrego, Coronel Pringles, Corones Suárez, Daireaux, Dolores, General Alvarado, General Alvear, General Arenales, General Guido, General Lamadrid, General Las Heras, General Lavalle, General Paz, General Viamonte, Hipólito Yrigoyen, Las Flores, Leandro N. Alem, Magdalena, Maipú, Monte, Navarro, Nueve de Julio, Pellegrini, Puán, Ramallo, Rauch, Rojas, Roque Pérez, Saavedra, Saladillo, Salliqueló, Salto, San Andrés de Giles, San Cayetano, Suipacha, Tornquist ,Trenque Lauquen, Veinticinco de Mayo, Villa Gesell, Villarino, Jesús Maria, Rio Tercero, Bell Ville, Almafuerte, Leones, Oliva, Villa Nueva, Corral de Bustos, Cosquín, Alejandro Roca, Etruria, Noetinger, Tancacha, Tanti, Villa del Totoral, Chajarí, Villaguay, Colon, La Paz, San Salvador, Villa Elisa, Cerrito, Urdinarrain, Libertador San Martín, Basavilbaso, Esperanza, Las Parejas, Rufino, Sunchales, Cañada de Gomez, El Trébol, San Genaro, General Acha, Toay, Ingeniero Luiggi, Gualeguay, Victoria, Nogoyá, Exaltación de la Cruz, General Villegas, Colonia Caroya y La Falda.

Región Cuyo (4): Santa Rosa, La Paz, Veinticinco de Mayo y Caucete.

Región NOA (15): Chilecito, Angel Vicente Peñaloza, Belén, Huillapima, El Carmen, Palma Sola, San José de Metan, Las Lajitas, General Güemes, Rosario de la Frontera, Rosario de Lerma, Termas de Rio Hondo, Añatuya, Gobernador Luis G. Pinto y Tafí del Valle.

Región NEA (17): General San Martin, Juan José Castelli, Machagai, Miraflores, Taco Pozo, Colonia Elisa, Bella Vista, Curuzú Cuatiá, Mercedes, Ituzaingó, Perugorria, San Vicente, 25 de Mayo, Capioví, Colonia Aurora, Panambí y San Antonio.

Región Patagonia (14): Cinco Saltos, Allen, Ingeniero Jacobacci, Centenario, Zapala, Plaza Huincul, San Martin de los Andes, Villa La Angostura, Gobernador Costa, Las Heras, Puerto San Julián, Tolhuin, Junín de los Andes y Rawson.

La representatividad de la muestra para cada categoría de análisis ha sido la siguiente:

GBA (con CABA): incluye un $32 \%$ de la población nacional. Cobertura de la muestra: $100 \%$ de la población.

Top 5: incluye un $13 \%$ de la población nacional. Cobertura de la mues- 
tra: $81 \%$ de la población.

Aglomerados Grandes: incluye un $11 \%$ de la población nacional. Cobertura de la muestra: $91 \%$ de la población.

Aglomerados Medianos: incluye un 8\% de la población nacional. Cobertura de la muestra: $97 \%$ de la población.

Aglomerados Pequeños: incluye un 8\% de la población Nacional. Cobertura de la muestra: $68 \%$ de la población.

Pueblos: incluye 24\% de la población nacional. Cobertura de la muestra: $18 \%$ de la población.

Para obtener la información fiscal, se trabajó fundamentalmente con el presupuesto ejecutado de recursos y gastos del año 2013 (cuenta de cierre). Las principales variables utilizadas fueron:

- Recursos corrientes (impuestos, regalías y tasas, entre los que se distinguen los principales: servicios generales, seguridad e higiene, conservación de la red vial municipal; así como también recursos corrientes provenientes de otros niveles de gobierno).

- Recursos de capital (entre estos se pueden diferenciar los provenientes del Fondo Federal Solidario).

- Gastos corrientes (se puede identificar el gasto en personal y en intereses de la deuda).

- Gastos de capital.

- Resultado financiero. 


\section{RE F E R E N C I A S B I B L I O G R Á F I C A S}

Arnstein, S. (1969). A ladder of citizen participation. Journal of the American Institute

Agüero Heredia, Amanda y Jan Casaño, Rosana (2009). “Los regímenes de coparticipación provincial de impuestos a los gobiernos subnacionales". Ponencia presentada en el X Seminario Red Muni: "Nuevo rol del Estado, nuevo rol de los municipios". Salta.

Agüero Heredia, Amanda y Jan Casaño, Rosana (2009a). “La autonomía económico-financiera legal versus la real en los gobiernos subnacionales". Trimestre Fiscal. N. ${ }^{\circ}$ 91, Instituto para el Desarrollo Técnico de las Haciendas Públicas. México D. F., pp. 255-288.

Asensio, Miguel (2006). La descentralización fiscal en el cono sur y la experiencia internacional. Análisis comparado y opciones. Osmar D. Buyatti Editorial. Buenos Aires.

Capello, Marcelo, Diarte, Gustavo y Freille, Sebastián (2013). “Finanzas Municipales 1993-2010 en el contexto del Federalismo Fiscal Argentino". Ponencia presentada en las IIas. Jornadas Iberoamericanas de Financiación Local. Universidad Nacional de La Plata (UNLP). La Plata, Argentina.

Caplan de Cohen, Norma (2000). "La clave de las finanzas municipales". Enoikos, $N^{\circ}$ 16, pp. 65-76.

Iturburu, Mónica (2000). Municipios argentinos. Fortalezas y debilidades de su diseño institucional. Instituto Nacional de la Administración Pública. Buenos Aires.

López Accotto, Alejandro; Martínez, Carlos; Mangas, Martín y Grinberg, Irene (2013). La provincia de Buenos Aires y sus municipios: los laberintos de una distribución anacrónica de recursos. Universidad Nacional de General Sarmiento. Buenos Aires.

López Accotto, Alejandro; Martínez, Carlos y Mangas, Martín (2014). Finanzas provinciales e impuesto inmobiliario en la Argentina. Últimos treinta años: más regresividad, menos equidad. Universidad Nacional de General Sarmiento. Buenos Aires.

Macon, Jorge (2000). “El federalismo fiscal y su financiación”. Enoikos, N 16. UBA, pp. 57-64.

Martino, Guadalupe; Romero, Francisco y Cadelli, Elena (2012). “Los sistemas tributarios municipales de la provincia de Buenos Aires". Documento de Trabajo N. 03/2012. Ministerio de Economía de la Provincia de Buenos Aires. La Plata.

Ministerio de Economía de la Provincia de Buenos Aires (2011). La autonomía de los municipios argentinos. Cuadernos de Economía N. ${ }^{\circ}$ 56. La Plata.

Ministerio de Economía de la Provincia de Buenos Aires (2014). Municipios de la provincia de Buenos Aires. Evolución de la situación económico-financiera 2007-2013. La Plata.

Porto, Alberto (1999). "Preguntas y respuestas sobre Coparticipación Federal de Impuestos". Documento de Trabajo N 17. UNLP. La Plata. 
Porto, Alberto (2004): "Finanzas Públicas Locales en la Argentina". Documento de Trabajo $N^{\circ}$ 57. UNLP. La Plata.

Rezk, Ernesto y Abraham, María (2013). “El desempeño de la autonomía económico-financiera de los gobiernos municipales en la provincia de Córdoba". Ponencia presentada en las IIas. Jornadas Iberoamericanas de Financiación Local. UNLP. La Plata, Argentina.

Sanguinetti, Pablo; Sanguinetti, Juan y Tommasi, Mariano (2001): La conducta fiscal de los gobiernos municipales en la Argentina: los determinantes económicos, institucionales y políticos. UNLP. La Plata.

Universidad Nacional de General Sarmiento y Secretaría de Asuntos Municipales de la Nación (2015). La estructura de la recaudación municipal en la Argentina: alcances, limitaciones y desafíos. Buenos Aires. 